University of New Hampshire

University of New Hampshire Scholars' Repository

Doctoral Dissertations

Student Scholarship

Spring 2009

\title{
The effects of documentation on young children's memory
}

Bethany Karen Benson Fleck

University of New Hampshire, Durham

Follow this and additional works at: https://scholars.unh.edu/dissertation

\section{Recommended Citation}

Fleck, Bethany Karen Benson, "The effects of documentation on young children's memory" (2009).

Doctoral Dissertations. 472.

https://scholars.unh.edu/dissertation/472

This Dissertation is brought to you for free and open access by the Student Scholarship at University of New Hampshire Scholars' Repository. It has been accepted for inclusion in Doctoral Dissertations by an authorized administrator of University of New Hampshire Scholars' Repository. For more information, please contact Scholarly.Communication@unh.edu. 


\title{
THE EFFECTS OF DOCUMENTATION ON YOUNG CHILDREN'S MEMORY
}

\author{
BY
}

\section{BETHANY KAREN BENSON FLECK}

BA, Western New England College, 2004

MA, University of New Hampshire, 2006

\section{DISSERTATION}

Submitted to the University of New Hampshire in Partial Fulfillment of

the Requirements for the Degree of

Doctor of Philosophy

in

Psychology

May, 2009 
UMI Number: 3363716

\section{INFORMATION TO USERS}

The quality of this reproduction is dependent upon the quality of the copy submitted. Broken or indistinct print, colored or poor quality illustrations and photographs, print bleed-through, substandard margins, and improper alignment can adversely affect reproduction.

In the unlikely event that the author did not send a complete manuscript and there are missing pages, these will be noted. Also, if unauthorized copyright material had to be removed, a note will indicate the deletion.

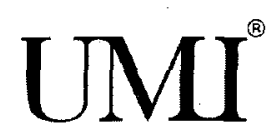

UMI Microform 3363716

Copyright 2009 by ProQuest LLC

All rights reserved. This microform edition is protected against unauthorized copying under Title 17, United States Code.

ProQuest LLC

789 East Eisenhower Parkway

P.O. Box 1346

Ann Arbor, MI 48106-1346 
This dissertation has been examined and approved.

Muchied. Jeché

Dissertation Director, Michelle Leichtman, Associate

Professor of Psychology

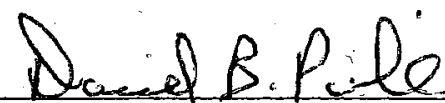

David Pillemer, Professor of Psychology and Paul Chair of Developmental Psychology

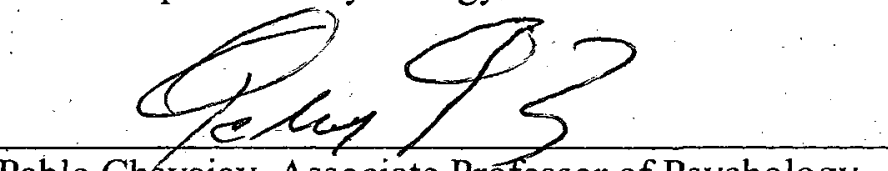

Pablo Chavajay, Associate Prơessor of Psychology

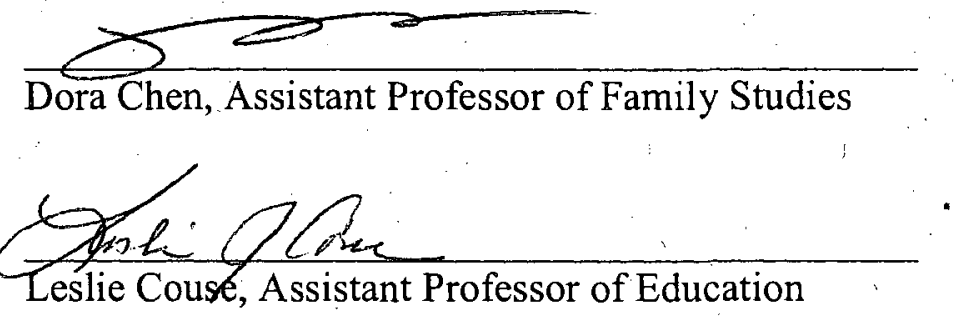

$\frac{4 \cdot 16 \cdot 09}{\text { Date }}$ 


\section{ACKNOWLEDGEMENTS}

This dissertation would have not been possible without the guidance and support of a group of individuals dedicated to the study of child development. Thank you to my helpful and encouraging committee members including Pablo Chavajay, Dora Chen and Leslie Couse. I would like to express personal gratitude to David Pillemer who has put extra time, consideration, and thought into my education and to this project in particular. Thank you to my fellow graduate students in the memory lab, you have all provided me with encouragement, laughter, and friendship. I could not have done this without the support of my parents, family and friends. Your love has carried me through and I am forever grateful. I appreciate the University of New Hampshire Graduate School for providing a Summer TA Fellowship Award in 2008. This funding was extremely helpful and allowed work to progress over the summer months. Finally, I want to thank my advisor Michelle Leichtman. Michelle, your wisdom and insights were invaluable to the success of this dissertation and to my personal and professional development. 
TABLE OF CONTENTS

ACKNOWLEDGEMENTS ..............................................................

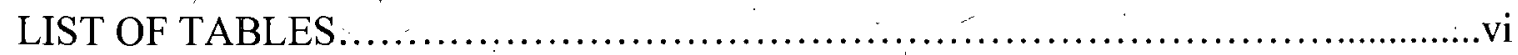

LIST OF FIGURES................................................................

ABSTRACT ........................................................................

CHAPTER $\cdots$ PAGE

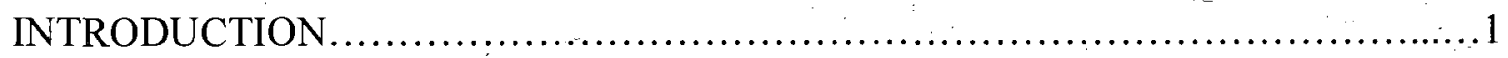

I. THE PRACTICE OF DOCUMENTATION ..................................... 4

PROPOSED ADVANTAGES OF DOCUMENTATION......................

II. PHOTOGRAPHS AND YOUNG CHILDREN'S MEMORY ...................11

III. CONVERSATIONS AND YOUNG CHILDREN'S MEMORY................ 17

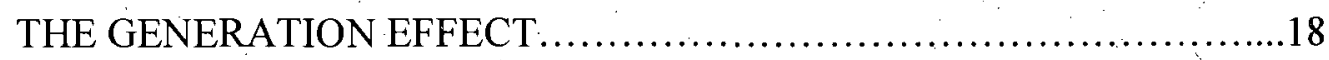

CONVERSATIONS AS SOCIAL INTERACTIONS.....................21

IV. THE COMBINATION OF PHOTOGRAPHS AND WORDS $\ldots \ldots \ldots \ldots \ldots \ldots \ldots .25$

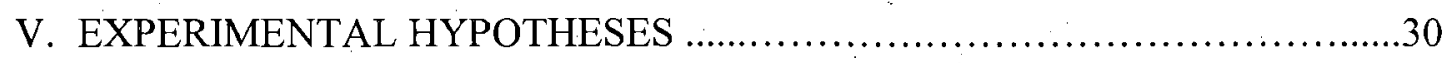

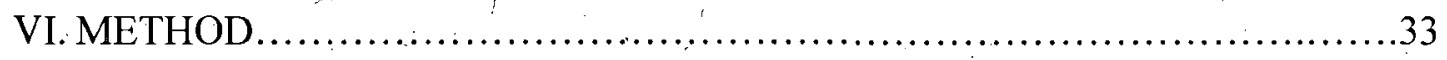

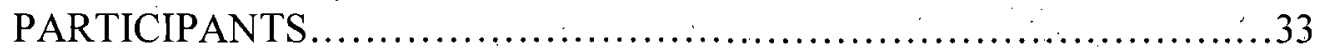

PROCEDURE FOR THE EARLY CHILDHOOD ENVIRONMENT

RATING SCALE REVISED (ECERS-R)................................38

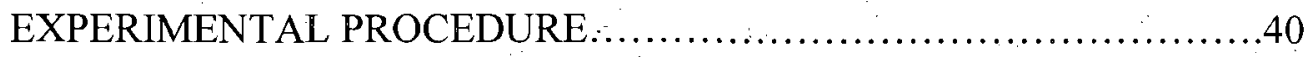

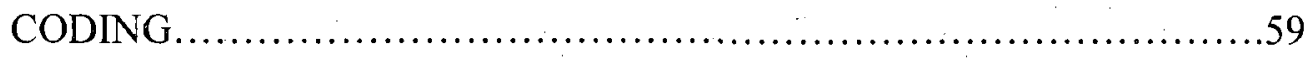

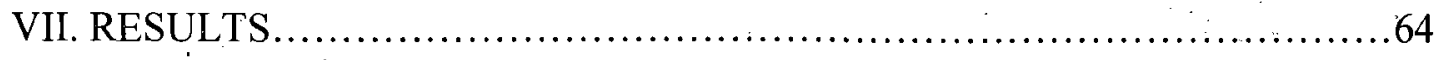




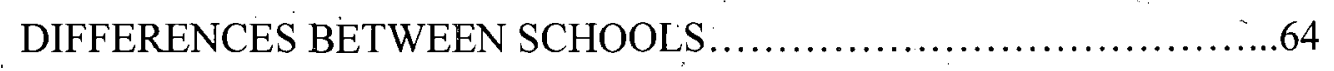

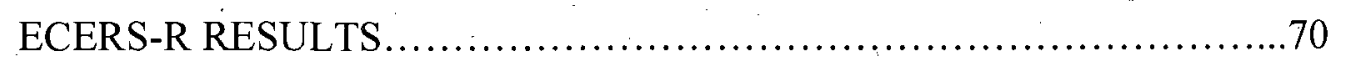

DIFFERENCES BETWEEN CONDITIONS ..........................72

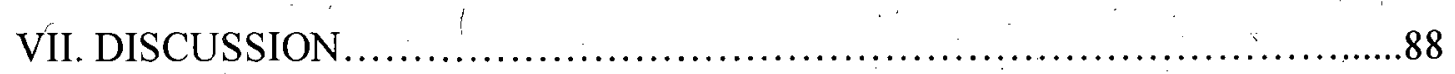

EPISODIC MEMORY .................................................... 90

SEMANTIC MEMORY ............................................ 93

CLASSROOM (AGE) DIFFERENCES............................97

CONCLUSION .......................................................... 100

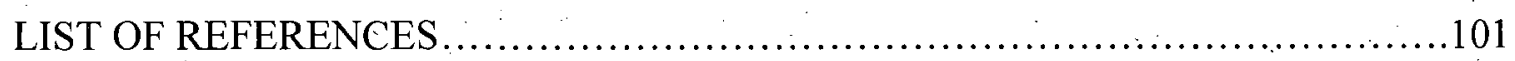

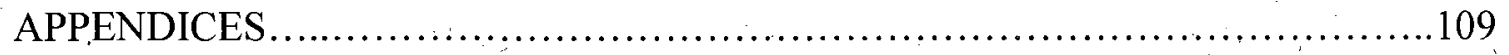

APPENDIX A SCRIPT OF SESSION ONE ..........................110

APPENDIX B SCRIPT OF SESSION TWO …......................114

APPENDIX C MEMORY INTERVIEW AND SCORECARD .........116

APEENDIX D MEMORY INTERVIEW SUMMARY SCORCARD...125

APPENDIX E TRASCRIPTION CODING TEMPLATE ..............131

APPENDIX F IRB APPROVAL LETTER..........................137 


\section{LIST OF TABLES}

Table 1. Descriptive Information for Participating Schools............................35

Table 2. Participants Demographic Information: Frequencies \& Mean Age..............37

Table 3. Memory Outcome Variables................................................66

Table 4. Average Scores on Memory Outcome Variables by School....................69

Table 5. ECERS-R Subscale Scores \& Mean Subscale Scores...........................71

Table 6. Average Scores on Event Questions by Condition.............................74

Table 7. Average Scores on the Specific Fact Questions by Condition...................82

Table 8. Average Scores on the Specific Fact Questions by Classroom...................83

Table 9. Average Word Count by Condition..................................... 85

Table 10 . Average Word Count by Gender ......................................... 86

Table 11. Average Word Count by Classroom..................................... 87 


\section{LIST OF FIGURES}

Figure 1. Participant Break Down Through Experimental Sessions.....................42

Figure 2. Documentation Poster.............................................. 48

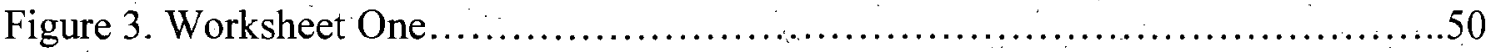

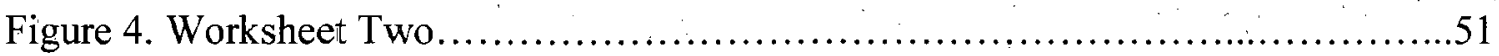

Figure 5. Control Worksheet One..............................................53

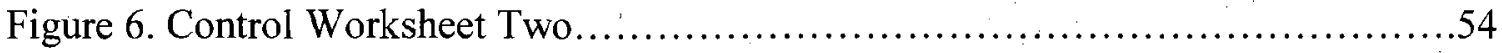




\begin{abstract}
THE EFFECTS OF DOCUMENTATION ON YOUNG CHILDREN'S MEMORY

by

BETHANY KAREN BENSON FLECK

University of New Hampshịe, May, 2009
\end{abstract}

\begin{abstract}
A central part of the Reggio Emila approach to early childhood education is the teaching method of "documentation." In documentation, educators extensively observe, record, and display young children's work through its progression. Educational and developmental literatures offer speculative claims and a theoretical basis supporting the facilitative effects of documentation on young children's memory. The current study is the first to empirically investigate the effects that documentation has on episodic and semantic memory. Sixty-six four and a half to 6-year-old children experienced a novel learning event. Two days later the children were reminded of the event and its content information using either documentation or worksheets, or they were not reminded. Following a three-week delay interval children completed a memory interview. In-depth coding and analysis of the interview revealed that children in the documentation and worksheet conditions remembered more information than children in the control condition. This evidence suggests that worksheets and documentation serve as effective reminders for episodic and semantic memory. These effects were particularly apparent in
\end{abstract}


open-ended (recollection) questions indicating that children were not just recognizing information but were actively recalling it. Analyses also revealed children's memory for information related to the props they held was remembered at a greater rate in the documentation and worksheet conditions. Furthermore, differences existed between younger and older children whereby kindergarten children remembered a greater amount during the memory interview than did preschool children. The present study suggests that documentation has positive benefits for young children's learning and memory supporting the claims of Reggio Emilia educators. 


\section{INTRODUCTION}

Across the United States early childhood education centers employ a variety of teaching methodologies in their curriculums. Head Start programs are founded on promoting school readiness by focusing on children's education, parents' participation, children's health and nutrition, and family services (Head Start, 2008). Waldorf education integrates practical, artistic, and intellectual elements focusing on natural rhythms of life (Petrash, 2002). Montessori programs try to enhance students' learning by emphasizing self-directed activity on the part of the child and the important role that physical activity plays in learning academic material (Lillard, 2005). An entirely different approach is seen when peering into a classroom inspired by educational practices originally developed in the city of Reggio Emilia, Italy. Imagine a classroom environment where the walls and shelves are filled with artwork, posters, and books that systematically review the learning that took place within that very room. These items might include drawings and sculptures broken into stages of their creation, photographs of children learning, children's expressions of their own thoughts, ideas, and feelings, and teachers' written narratives reviewing how learning events occurred and the information that children and teachers studied (Project Zero, 2001). What are the effects of documents like these on young children's learning? Do photographs and narratives of classroom activities aid children's recall of event information and educational material? 
The goal of this research project is to describe the effects that the practice of documentation, used within the Reggio Emilia approach to early childhood education, has on young children's memory. To begin, a brief review of the Reggio approach is provided, followed by a focused explanation of the method of documentation practiced within the classroom. Next, the claims made by Reggio educators concerning the impact of documentation on young children's learning and memory are presented.

Focus then turns to developmental literature on two of the inherent characteristics of documentation that have implications for children's memory: photographs and narratives. Documentation typically includes children's photographs and accompanying narratives about classroom activities and their educational content. Current research exploring the use of photographs as representational reminders for young children is summarized. Although the narratives can take many forms, a predominant form is photocaptions, or verbatim quotations taken from children's conversations while they are engaged in photographed tasks (Helm, Beneke \& Steinheimer, 1998). Because there is limited research on the effect of direct text feedback on memory, research on the general effects of conversation on young children's memory is reviewed. Finally, research examining the facilitative effects on children's memory of illustrations accompanying text is reviewed. This is the combination of the verbal and pictorial aspects that are seen together in documentation.

Although the developmental literatures on photography and conversation are relevant, to date no quantitative research has directly assessed the effects of Reggio-style 
documentation on young children's memory. The present study was explicitly designed to do so. The central research question was the following: What are the effects of documentation on children's episodic and semantic memories within an educational context? 


\section{CHAPTER I}

\section{THE PRACTICE OF DOCUMENTATION}

The practice of documentation is inspired from the Reggio Emilia approach to early childhood education. This approach is best explained through discussion of its various pedagogical assumptions and methods. First and foremost, the approach is based on the fundamental belief that children have rights rather than needs. This means that Reggio educators value and trust in children's abilities. For example, children have the ability to climb and are encouraged to do so safely. This is in contrast to the view that

children need protection and are told not to climb in fear that they might hurt themselves (Hewett, 2001).

Reggio's founder, Loris Malaguzzi, was strongly influenced by the constructivist viewpoint of Jean Piaget in which children play an important role in their own development, actively constructing knowledge and making sense of their world (Malaguzzi, 1998). In the Reggio approach the child is viewed as a researcher. Children engage in projects in which they form hypotheses, observe, discuss, ask, represent, and revisit material. Children are considered rich in resources, strong and competent, with high potential, plasticity, openness, and a desire to grow (Rinaldi, 1998). Thus, educators emphasize the importance of truly listening to the child's thoughts, respecting their ideas, and taking their work seriously (Hewett, 2001). 
The Reggio practices noted above reflect a social constructivist perspective, emphasizing children's construction of knowledge within the context of social relationships (Rinaldi, 1998, Vygotsky, 1978). In this view, knowledge is built through active collaboration, dialogue, conflict, and cooperation with peers and adults, and conflicts and recognition of differences are considered to be a driving force in children's growth (Hewett, 2001, Rinaldi, 1998). .

The Reggio approach holds that there are multiple forms of knowing, expressing, demonstrating, and interpreting knowledge. Thus, the curriculum is not planned in the traditional sense, and children and teachers work together to determine the course of their investigations, acting as co-learners and collaborators (Hewett, 2001). Both children and teachers are considered to be researchers in the classroom (Rinaldi, 1998). The primary form of instruction takes place in project work, or extended, in-depth investigation of particular topics chosen according to the mutual interests of children and teachers (Katz, 1998). Teachers facilitate project work by observing children's curiosity and motivation, documenting their work, and reflecting on their progress, taking care to be actively present but not intrusive (Hewett, 2001). Teachers carefully outline objectives, hypothesize, and project where the children's work might go, while still being flexible and able to adapt as the work proceeds. This type of planning is known in Reggio as progettazione (Rinaldi, 1998). Furthermore, ideas are communicated using many 'languages' including writing, drawing, sculpture, dance, painting and drama. In this way children and teachers create the curriculum based on their own interests, which are then explored through various representations (Edwards, Gandini \& Forman 1998; Hewett, 2001; Katz, 1995; Project Zero, 2003). 
Documentation is said to be at the heart of the Reggio Emilia approach (Fawcett \& Hay, 2004). Reggio educators use documentation to fulfill their role as researchers in the classroom as a part of the progettazione planning system. This practice of documentation involves many layers of work, including listening, observing, gathering, interpreting, and discussing material (Katz \& Chard, 1997, Rinaldi, 1998). In this way, the practice involves much more than simple observation and record keeping; children's memories, thoughts, and ideas are recorded including samples of their work at multiple stages of completion and in multiple ways, in a continuous spiral of activity (Katz \& Chard, 1997; Thornton \& Brunton, 2005; Wurm, 2005).

The practice of documentation often involves transcribing children's conversations and pairing them with photographs of their activities. Photographs and narratives are made visible through displays on panels, exhibits of artifacts, and through books, notebooks, diaries, audiocassettes, messages, and letters (Gandini, 2004). These displays are continuously available to children and adults, covering the walls of classrooms and hallways, described in some cases like a second skin (Project Zero, 2001).

Helm, Beneke, and Steinheimer (1998) provide an example of documentation that illustrates the practice. A class of 3- and 4-year-old children embarked on an in-depth study of the U.S. mail system lead by their two female teachers. During a story being read to the class, one character sent a letter to another character which spawned many questions from the children. After brainstorming questions and theories concerning how mail is delivered the teachers and children decided to further investigate the mail system. 
The teachers planned specific goals such as giving children an opportunity to provide a service to their school and helping them begin to understand how to investigate and research a topic.

The next step of the U.S. mail study was for children to develop and operate a mail system within their school, which they then ran for four weeks. The system involved making and selling stamps, picking up and delivering mail, sorting mail, and constructing mailboxes, mailbags, and even a mail truck. Each element gave rise to smaller studies. For example, while creating mailboxes for the school's classrooms, children reflected on what their mailboxes at home looked like and what those at school should look like.

The children and teachers documented their work by creating final reports of the various aspects of the project, making several large classroom books showing how elements of the project were constructed (e.g., the mailboxes) and a final book illustrating the overall mail system using a flowchart as a reference. Each book used phötographs and brief captions that described various activities the children had engaged in. For example, in the mailbox book a picture appeared that showed seven of the children working hard to paint several mailboxes. The photo-caption underneath read, "Some of us painted lots of cardboard boxes for mailboxes. They used many different colors. Some of us counted the mailboxes to make sure that we had enough for the whole school. We needed 20 mailboxes altogether (Helm et al., 1998, p. 162)." Another book was made about the mailbags. In this book a photograph depicted one young boy carrying many letters in his hands, of which some were falling out. The picture caption read, "In the beginning, we did not have a mailbag. When some of us carried the mail, they dropped it 
all over the place. We decided to make a mailbag (Helm et al., 1998, p. 170)." In yet another example from the mail truck planning board the photo-caption under one child depicted in a real mail truck read, "First we looked at Mr. Tim's mail truck (Helm et al., 1998, p.170)."

It is clear in this example how documentation contributes to project study in the Reggio Emilia approach to early childhood education. The children's interests determined the subject, they worked collaboratively with teachers to conduct research, and they documented their progress throughout. The documents created used both photographs and narratives, and children revisited them often as they reviewed the books and panels and shared them with visitors.

\section{Proposed Advantages of Documentation}

A great deal of anecdotal evidence exists concerning the advantages that the method of documentation has within early childhood education. Reggio enthusiasts claim that documentation enhances children's learning, in part because revisiting their own and others' work increases children's understanding. Enthusiasts also note that documentation prompts adults to take children's ideas and work seriously, enables greater parent participation, allows for continuous planning and evaluation of children's and teachers' work, and makes learning visible to the entire community (Goldhaber \& Smith, 1997; Katz \& Chard, 1997: Project Zero, 2001, 2003; Rinaldi, 2006, 1998; Thornton \& Brunton, 2005; Wurm, 2005). Furthermore, documentation is said to record children's growth over time, to develop a complex and detailed picture of the child in all developmental domains, and to provide a resource for the community of educators to 
understand children's learning better (Wurm, 2005). Of particular interest are claims made concerning the enhancement of children's learning and memory.

Concerning the advantages of documentation for learning, researchers claim that documentation contributes to the range and depth of children's learning, providing children with a kind of debriefing or revisiting where new understandings are formed, clarified, and strengthened (Katz \& Chard,1997). Katz (1995) has further posited that documentation allows children to demonstrate the extent and depth of learning in ways that standardized tests and checklists do not. Documentation enables reading and interpretation as well as revisiting and assessment, which contribute to children's knowledge-building processes (Rinaldi, 2006).

Concerning the advantages of documentation on memory, much of the anecdotal evidence is based on the opportunity that documentation provides to revisit and reflect on work. Documentation is said to provide the material for reflection which takes place after each learning session and continuously as documentation is displayed in the classroom environment (Fawcett \& Hay, 2004). For example, Wurm (2005) cites various ways that documentation is used within the classroom including these memory-related objectives; "For children to reflect on their own work (pp. 107)", and "for children to connect to and reflect on other children's work (pp., 107)". Hewett (2001) suggests that documentation provides children with a visual memory of their work that encourages the revisiting and explanation of old ideas as well as the inspiration for new ideas.

Forman (1999) relates documentation to the accessibility of knowledge and how well children index principles. Forman claims that documentation indexes knowledge and 
if children can remember a tag or index then they can retrieve the whole principle. Indexing occurs for example, when the teachers write captions below photographs of encounters that epitomize a developmental principle.

Charlina Rinaldi, who worked with Loris Malaguzzi for many years and is now the pedagogical director of the infant-toddler centers and preprimary schools in Reggio, claims that documentation provides an occasion for intense daily communication and reflection. She affirms that it essentially supports memory processes, hypothesizing that significant reinforcements can be offered to the memory system by the images, voices, and notations within documentation (Rinaldi, 1998). The documents become memory enhancing materials as the children actively revisit them, necessitating their capacity for concentration and interpretation (Rinaldi, 2006). She writes:

"Documentation supports children's memory, offering them opportunity to retrace their own processes, to find confirmation or negation, and to selfcorrect: Documentation allows for children to make self-evaluation and group evaluation, conflict of ideas, and discussion (Rindaldi, 1998, pp. 122)."

With an understanding of what the Reggio Emilia Approach entails and the specific practice of documentation, attention will now turn towards the individual effects of its two primary characteristics, photographs and conversations. It is, after all, the recorded conversations and captured photographs which provide the content of the documentation itself. Much research has been conducted that aims to understand how children are able to use, comprehend, and remember both photographs and conversations. 


\section{CHAPTER II}

\section{PHOTOGRAPHS AND YOUNG CHILDREN'S MEMORY}

Recently, much research in memory development has focused on the effects of representational reminders such as live demonstrations, videos, photography, and scale models on young children's recall. Taken together, the results suggest a strong developmental trend across early childhood. As children age they become more aware of the symbol-referent relationship and are able to use certain symbols to reinstate single event memories (e.g., Deocampo \& Hudson, 2003; DeLoache \& Burns, 1994; Hudson, Sheffield, \& Deocampo, 2006; Sheffield \& Hudson, 2006; Troseth \& DeLoache, 1998).

Photographs come in many forms and serve many functions. DeLoache, Pierroutsakos, and Troseth (1996) point out that all pictures can be seen in two ways: as displays in and of themselves (i.e., images) and as representations of something else (i.e., referents), such as objects out in the world. The dual representation hypothesis suggests that in order to understand a picture, the viewer must simultaneously grasp it as an image and a referent. In other words, the viewer must know that a picture is a concrete object in and of itself as well as an abstract symbol of the particular information it depicts (Deocampo \& Hudson, 2003). To respond to both aspects of this dual representation demonstrates the achievement of a mature pictorial competence (DeLoache \& Burns, 1993). 
Pictorial competence develops throughout early childhood. Beginning in infancy, researchers have found that three-month-olds are able to recognize familiar faces, such as those of their mothers, as well as objects that are depicted in photographs (Barerra \& Mayrer, 1981; DeLoache, Strauss, \& Maynard, 1979). However, recognition alone does not indicate comprehension. Within toddlerhood a major developmental shift occurs in pictorial competence. This shift, which occurs between 24 and 30 months of age, has repeatedly been shown in experimental studies, each indicating a much greater proficiency among older than among younger toddlers. In one study, researchers employed an object retrieval task in which children were presented with a picture showing the location of a hidden toy in a real room. The task for children was to use the information from the picture to successfully locate the toy in the room. The 24-month-old children performed extremely poorly, finding the toy without error on only 13 percent of retrieval trials whereas the 30 -month-old children were much more successful, finding the toy without error on 72 percent of retrieval trials (DeLoache \& Burns, 1994). The 1994 study was a replication of an earlier study (DeLoache, 1991) which also demonstrated that 30-month-old children understood the relationship between a picture and its referent.

Other methods have been employed with similar results, including pretend transformation tasks. In these tasks, children must imagine the transformation of an action and correctly select a pictorial representation of its outcome. For example, in one episode the researcher used an empty milk carton and pretended to pour milk from it over a toy animal. The child was then given the choice of three picturès, one of the toy animal with no change, one of the toy animal with milk on it, and one of the toy animal with an 
unrelated change such as a red mark on it. Results indicated that 20 to 24 -month-old children were significantly worse at choosing the correct transformation compared to 27 to 30-month-old children. The authors related these findings to the ability of the older children to understand the symbolic mapping between the referent and the picture (Harris, Kavanaugh \& Dowson, 1997).

On the whole, current research indicates that at 24-months of age children have a limited understanding of the picture-referent relationship, but by 30-months they are able to demonstrate a much clearer and more mature level of understating. However, even at 30 months this understanding may not facilitate optimal performance equally across all situations (DeLoache, 1991).

Based on abundant literature on the development of children's understanding of the picture-referent relationship, one might suspect that children would need a mature grasp of this relationship before photography could serve as an effective reminder for memory. (DeLoache et al., 1996; Deocampo \& Huson, 2003). Nonetheless, it is not clear that mature pictorial competence is a necessity for pictures to adequately reinstate young children's memory. Indeed, some studies have provided evidence that photographs can reinstate memories prior to the full development of pictorial competence, as early as 24months-old (DeoCampo \& Hudson, 2003; Hudson et al., 2006).

Several research methods have been utilized to determine when pictures can be used successfully as a reminder of previous events for young children. Most of this research concentrates on the use of photography to reinstate memory. Reinstatement occurs when the individual is reintroduced to a past activity by re-experiencing a portion 
of it through brief exposures to specific parts of the original event (Hudson et al., 2006). In this body of literature, the exposure takes the form of a picture which depicts some portion of the child's original experience. Sheffield and Hudson (2006) studied the effects of photograph reinstatement on recall in children as young as 18-months old using a reminder task. This experiment employed a deferred imitation paradigm consisting of three phases. In phase one; children learned to produce novel actions in the laboratory. After a retention interval of ten weeks, children entered phase two, in which they saw either a video or photograph of the laboratory event (both with accompanying narration). In the final phase, 24 hours after phase two, researchers assessed children's memory by noting the number of correct actions they produced. The findings indicated that videos did reinstate 18-month-old children's memories but that photographs did not. The children who saw pictures produced no more actions then those in the control conditions, and produced significantly fewer than those who viewed the video reminder.

Similar methods have been used to test the impact of photographs as reminders on older toddler's memory. Deocampo and Hudson (2003) employed a deferred imitation paradigm with 24 and 30-month-old children. In this study, children observed an experimenter performing novel three-step actions. After the retention interval-(2-4 weeks) half the children were presented with pictures of the actual event and of never seen events (the reminder group) while the other half of the children were presented with neutral pictures from a picture book (the no-reminder group). After showing the pictures, the researcher asked the children to verbally recall the original event and to then physically perform the tasks. Results indicate that photographs are effective in reinstating both 24 and 30-month-old children's memory of a single event: For both ages, children in the 
reminder group performed significantly more actions then those in the no-reminder group. However, it should be noted that overall levels of recall were low, far from reaching ceiling levels. Further analysis revealed an age difference, with 30-month-old children recalling more activities than 24-month-old children.

These findings suggest that photographs can reinstate memory of a single event among children as young as two years, while understanding of the picture-referent relationship begins six months later, at 30 months. Two possible interpretations have been suggested. First, children might not need to have pictorial competence to use photographs as reminders. Reminding would thus be an implicit process where children recognize the similarity between the reminder (picture) and the previous event. In this case children would not explicitly realize the reminder is a symbol while it would still provide enough information for reinstatement (Deocampo \& Hudson, 2003).

The second interpretation is based on findings from the experimental task used to assess pictorial competence. As previously explained, researchers have employed objectretrieval tasks in which children must find hidden toys based on information provided to them in pictures. This method assessed children's pictorial competence as well as their ability to use pictures successfully as a reminder of where the hidden object is located. DeLoache and Burns (1994) found that photographs did not guide 24-month-olds' search behaviors whereas they did guide those of 30 -month-olds. In the second interpretation, dual representation is necessary for pictures to be used as reminders but the understanding progresses differently based on the experimental task (i.e. reminder task vs. object retrieval task). Object retrieval tasks must present more of a challenge to the 
child's understanding of the symbolic nature of the representational reminder than do reminder tasks (Deocampo \& Hudson, 2003; Hudson et al., 2006).

Research examining children's use and understanding of photographs leads to two major conclusions. First, there exists a strong developmental trend in understanding the representational function of symbolic reminders, such that before 30 -months of age children do not have a well-developed understanding of the picture-referent relationship. Second, there is a continuing question concerning the necessity of pictorial competence for the use of photographs to reinstate memory. In picture reminder tasks (which use deferred imitation paradigms) successful reinstatement of single event memories has been demonstrated in children as young as 24 months. This indicates that children do not need full pictorial competence to use photographs as reminders. On the other hand, in object retrieval tasks, successful retrieval occurs at 30 -months. This indicates that dualrepresentation is needed to solve them.

Although more work is needed to fully understand the role that dual representation plays in the use of photographs as reminders, young children can clearly use photographs as reminders in many situations. The practice of documentation provides a perfect opportunity to further understand the effects that pictures have on young children's memory. 


\section{CHAPTER III}

\section{CONVERSATIONS AND YOUNG CHILDREN'S MEMORY}

In the Reggio Emilia practice of documentation photographs are often accompanied by quotations which have been recorded and posted on display panels as photo-captions. These quotations come from the children as they work on projects or are interviewed about their work by their teachers. Other project narratives are used as well which can take the form of stories written for and written by children, teacher's journals, and narratives about the learning event or content, letters, or visual displays (Helm, et al., 1998). Due to the nature of the present study the narratives that will be the focus are those which are in the form of photo-captions using direct quotations from children.

Outside of the context of Reggio documentation, children are not usually: presented with verbatim feedback in their own words or recounts of narratives they helped to create. For this reason developmental and educational literatures present little research on the effects that direct text feedback might have on young children's memory. However, much research has investigated the impact that conversations have on memory. Although not exactly the same, the study of conversations does provide relevant data which contributes towards understanding the possible impact that photo-captions have on children's memory in Reggio classrooms. 
"Developmental research supports the essential connection between talking about an event and remembering it later on." (Pillemer, 1998, p. 127) Researchers have suggested overarching effects that adult-child conversations might have on children's memory. First, when talking about an event, the labels and descriptions that adults provide assist the child's verbal encoding and later reporting (Fivush, Pipe, Murachver, and Reese, 1997; McGuigan \& Salmon, 2004). Second, when a conversation takes place after an event, children are provided with two opportunities to encode the information, during the event itself and during the post-event conversation. Holding conversations at both points allows children extended time to process event-related information and helps them organize event representations in memory. Conversations after an event may be an effective way of reinstating and preserving the event in memory (McGuigan \& Salmon, 2004).

\section{The Generation Effect}

Another effect that conversations have on children's memory is known as the generation effect. The generation effect states that self-generated information is better remembered than information that is read or heard. Researchers have found that in experiments the words a participant generates are recalled at a higher rate than the words an experimenter provides (Lin, Hendriks, \& Craik, 2007; McFarland, Duncan, \& Bruno, 1983; Slamecka \& Graf, 1978). For example, Slamecka and Graff (1978) conducted a series of studies in which groups of undergraduate students were asked to produce a word that began with a given letter and was related to a stimulus word by a specified rule. For example, if the letter provided was $f$, the rule was to produce a synonym, and the stimulus 
word was "rapid," an appropriate participant response would be to generate the word "fast." The findings confirm the existence of the generation effect and further specify the range of circumstances under which it appears. Participants who generated the words recognized more of them and were more confident about doing so than participants who only read the words. The effect persisted across a wide array of encoding rules as well as manipulated variations in the procedure (including under the unique demands of multitrial free recall testing). Furthermore, the effect required that no externally provided retrieval cues were necessary in order to bring the phenomenon about and that it did not habituate with repeated exposure to the same words. The authors conclude that the generation effect is a robust effect and that it manifests itself across a variety of testing procedures, encoding rules, and other situational changes (Slamecka \& Graf, 1978).

Many other research studies have also confirmed the existence of the generation effect in adults (Dosher \& Russo, 1976; Johnson, Taylor \& Raye, 1977; McFarland et al., 1983) although few have attempted to understand the development of the effect using child participants. One study specifically sought to understand if the generation effect requires some amount of cognitive maturity as is seen with other deliberate rehearsal and organization strategies. Reseárchers recruited 60 children ranging in age from 7.6 years old to 12.9 years old and employed a task similar to (but easier than) the one previously explained (i.e., children were required to either generate or study category or rhyming words). Upon testing, the recall results indicated that children showed substantially greater memory for subject-generated words as compared to experimenter-generated words. The generation effect was clearly present at all age levels but did show an upward trend in which recall increased with age. The authors suggest that a certain level of 
cognitive maturity is needed to fully benefit from the memory enhancing effects of the internal generation of to-be-recalled items, but the effect was still apparent in children as young as 7 years old (McFarland et al., 1983).

Results from conversational literature support the possible existence of the generation effect in conversations. McGuigan \& Salmon (2004) found that during conversations child-generated labels are recalled at a greater rate than adult-verbalized labels. It seems that the words that a child speaks of their own accord are the aspects that are most readily remembered. In this way children are not simply importing parental conversational content into their own accounts but rather are heavily contributing to what they themselves subsequently report (McGuigan \& Salmon, 2004). Another researcher, Robyn Fivush and her colleagues supported this notion and contended "when children do recall the same information across recall trials, they are much more likely to recall what they themselves recalled previously than what an adult has told them about the event (Fivush, Hamond, Harsch, Singer \& Wolf, 1991 p. 387)."

The generation effect is of particular interest in regards to the current research study. Photo-captions, used in dócumentation, highlight children's self-generated contributions to conversations and in doing so should impact the availability of children's memories of the events being documented. The studies available on the generation effect are limited to procedures in which adults and children are asked to read and then respond, leaving out data on young children. More importantly the current studies also neglect the possibility of a generation effect for words which are spoken during a naturally occurring conversation or a conversation regarding content learned in an educational context. 


\section{Conversations as Social Interactions}

A final effect that conversations have on young children's memory draws on Vygotskian and social interaction perspectives, which both affirm that children learn narrative skills in the context of adult-guided conversations (Fivush, 1991; Vygotsky,1978).

During conversations with social partners, particularly mothers, young children learn to represent their experiences in an organized form, structuring their remembered experiences according to the models presented (Fivush et al., 1991; Tessler \& Nelson, 1994). Conversations help children understand an event by guiding the child's attention to its significant aspects and by highlighting its 'causal and temporal structure' (Boland, Haden \& Ornstein, 2003; Haden, Ornstein, Exkerman \& Didow, 2001). In such conversations, "distinctive strategies for representing and sharing personal eventmemories are co-constructed" (Pillemer, 1998, p.21). Acquiring these strategies enables the child to communicate more successfully with others, which permits rehearsal of the memories and enhances the likelihood that they will be maintained in autobiographical memory (McGuigan \& Salmon, 2004; Nelson \& Fivush, 2000). A study conducted by Edwards and Middleton (1988) confirms the impact of conversations on young children's memory and on their ability to extract meaning from photographs. In this research, mother and child conversations surrounding family photographs were observed. It was concluded that mothers were not simply talking about the pictures but were implicitly modeling how to remember through the narration of the pictures. What should be 
remembered, the relationship of events, and how the photographs work as reminders were all present in the conversations.

Adults and children who are experiencing or conversing about an event together may come to construct the event in a way that makes it more accessible to them in the future (Haden et al., 2001). Adults' talk is thus a form of extraneous knowledge made available to the child. It guides children and provides them with all the advantages that prior knowledge has on memory, such as assisting encoding and retrieval (McGuigan \& Salmon, 2004). As children's task experience increases they rely less and less on the adult to provide the overall guiding structure and more on their own skills (Fivush, 1991).

The majority of research on the effects of conversation on children's memory has focused on maternal reminiscing style. Because the social interaction perspective places the focal point of children's autobiographical memory development on parent-child conversations it is clear why research has concentrated on understanding the nature of these conversations more deeply. Within this literature three major conclusions have been found, (1) children's own memory style is reflected in the style used by their parents, (2) the events that are discussed with parents are more likely to be recalled at a later time period than those that are not, and (3) maternal reminiscing style can predict children's recall (Fivush, 1991; Fivush et al., 1991; Handen et al., 2001; McGuigan \& Salmon, 2004; Pillemer, 1998; Tessler \& Nelson, 1994).

Expanding upon the last conclusion, maternal reminiscing style has been divided into two domains, high elaborative and low elaborative. High elaborative mothers provide strong narrative structure for their children's memories and work to confirm or 
extend their child's contribution to the conversation. In comparison with low elaborative mothers, they tend to engage in lengthy conversations about the past with their children, provide narrative scaffolding for their children's memories, ask elaborative questions, and embellish and add details to co-constructed narratives (Fivush, 1991, Fivush, Reese, \& Haden, 2006; McGuigan \& Salmon, 2004; Pillemer, 1998). High elaborative mothers also use more open-ended questions and confirmations, provide a generous amount of new information to the conversation and demonstrate a willingness to follow in on children`s memory provisions (Cleveland \& Reese, 2005). Low elaborative mothers provide their children with less narrative structure, provide fewer embellishments, and often repeat their questions (Fivush, 1991; Pillemer, 1998).

Researchers have found that mothers who use a high elaborative style have children who show high recall and responding during their conversations (Cleveland \& Reese, 2005; Reese, Haden, \& Fivush, 1993). Not only have concurrent conversational effects been observed but effects have also been found on children's later memory performance. High elaborative mothers have children who recall more information about past events both initially and later when reminiscing independently (McGuigan \& Salmon, 2004). Leichtman and colleagues report that maternal conversational style predicts the information provided by children during mother-child interviews about nonshared events, and also predicts later performance in interviews where the mother is not present (Leichtman, Pillemer, Wang, Koreishi \& Han, 2000; Leichtman, Wang, and Pillemer, 2003). The conclusion of this body of literature is that children acquire narrative structure and content information through the social interactions of mother-child 
conversations. Children's memory is without a doubt affected by the conversations which take place between themselves and their adult partners.

Although conversations are different than the direct text feedback children receive when exposed to Reggio Emilia documentation, the conversation literature does provide insights into understanding how documentation might affect children's memory. First, as demonstrated with the generation effect, when individuals have the opportunity to generate words in laboratory or conversational contexts, they remember those words at a higher rate than words that were provided to them (McFarland et al., 1983; Slamecka \& Graf, 1978). When children revisit their own speech during documentation it is possible that the generation effect occurs and is exággerated. Second, it is possible that documentation in the Reggio context serves a similar function as elaborative conversation about a past learning event. Reggio educators observe that documentation induces adult and child conversations (Goldhaber \& Smith, 1997; Katz \& Chard, 1997: Project Zero, 2001, 2003; Rinaldi, 2006, 1998; Thornton \& Brunton, 2005; Wurm, 2005). It might be that the documentation itself and the conversations that arise because of it provide a structure for remembering just as maternal conversation would, indicating to children what is important to remember and how to remember or talk about it later on. 


\section{CHAPTER IV}

\section{THE COMBINATION OF PHOTOGRAPHS AND WORDS}

The research discussed thus far has focused on the use of photographs and the effects of conversations and self-generated words on young children's memory. Researchers have also investigated children's memory processes when both pictures and words are present. Work on this topic is particularly relevant to common educational practices in early childhood classrooms, including the use of illustrations in children's storybooks. It also provides insights into the effects that visual aids, such as documentation, have on children's learning.

Although preschool and kindergarten children do not usually read proficiently by themselves, their parents and teachers often read to them. Much research has investigated the effects that pictorial illustrations accompanying a text have on a reader's memory. It ' has been suggested that pictures serve many functions in children's storybooks. Fang (1996) lists six roles in particular. He asserts that pictures help establish the setting, define/develop the characters, extend/develop the plot, provide a different viewpoint, contribute to text coherence, and reinforce the text. He also suggests that pictures have broader benefits, such as providing motivation to the reader, promoting creativity, serving as a mental scaffold, fostering aesthetic appreciation, and promoting children's language literacy. 
Another researcher, Levin (1981), suggests five different functions that pictures serve during text processing. First, pictures can be decorative (or "decorational") when they simply decorate the page but have no relationship to the text. Second, pictures can be representational when they mirror part or all the text content. Third, pictures can be organizational when they provide a useful structural framework for the text content (i.e. diagrams). Fourth, pictures can be interpretational when they are used to help clarify difficult text. Fifth, pictures can be transformational when they are used as memoryenhancing tools through their mnemonic components.

For several decades, researchers have investigated the impact of illustrations accompanying text on children's content comprehension and memory. Overall, this body of literature has consistently found that pictures have a facilitating effect. Carney \& Levin (2002) conducted a meta-analysis of related work with the goal of understanding exactly how pictures can complement text. They concluded that there are no benefits from Levin's (1981) decorative function while all the other functions are helpful for children's content comprehension. Levin and Mayer (1993) suggest that the other functions might work because they make the text more concentrated (i.e., focusing the reader's attention), eliminate excessive words making the text more compact and concise, and increase the text coherence.

Other researchers have worked to understand how and why pictures accompanying text facilitate memory. Rusted \& Hodgson (1985) experimented with the type of text presented alongside pictures to see if the picture facilitation effect differed for expository/factual or story text. In this study, children read passages about unusual 
creatures that included factual descriptions along with fictitious stories. Immediately after reading, children were asked to recall what they could from the text. The researchers found that illustrations increased children's overall memory and that this was especially true for expository text.

Digdon, Pressley and Levin (1985) investigated whether the content conveyed in illustrations needed to completely or partially overlap the text to be effective in facilitating comprehension. They also explored whether instructions to imagine images were equally facilitating as the presentation of real illustrations. Three- to five-year-old, children in their study saw pictures that either fully or only partially represented the content of accompanying prose, and were later probed for prose comprehension. Imagery directions also varied so that children received instructions such as "try to imagine everything in your head that is 'going on (p.141)" or, alternatively, "just listen carefully" (p.141). Results revealed that imagery instructions did not benefit children and that pictures did not have to overlap with the prose content completely to yield learning benefits, but did need to be consistent with the prose (Dighdon et al., 1985).

Digdon and colleagues' study confirmed the facilitative effects of illustrations that accompany text for three- to five-year-old children. In á recent article, Greenhoot and Semb (2008) further investigated age-related changes in picture facilitation effects for prose learning during early childhood. In this study, sixty preschool children were broken up into four conditions: (1) verbal with pictures (2) verbal with irrelevant pictures (3) verbal only (4) pictures only. The researchers presented each child with a story, a distracter puzzle task and a memory interview. A week later the children were 
interviewed again. Findings indicated that the degree to which illustrations enhanced memory increased across the preschool years. Children in the "verbal with pictures" group had similar memory performance to those in the other verbal groups at the low end of the age range, but as children aged those in this group performed significantly better than the others. The verbal and irrelevant pictures had no facilitative effects. Overall, this pattern of results suggests that relevant pictures do more than just make text more interesting for children to look at.

Why might pictures facilitate text comprehension, especially among older preschool childrèn? Paivio $(1970,1986)$ proposed a dual coding hypothesis in which exposure to information both verbally and pictorially results in the construction of separate verbal and pictorial representations that are connected in memory. In this way, when verbal and pictorial material is presented together it should be easier to recall than information presented in only one of the two modalities. The two representations should provide redundant retrieval routes. The age effect that Greenhoot and Semb (2008) documented may be a function of the availability of working memory in young children. Instead of using an automatic encoding process as older children do, younger children may need to attend to and encode both the verbal and pictorial details and then connect them, in a process that heavily taxes working memory. 
Based on this body of literature it is clear that illustrations and text presented together have facilitating effects for young children's text comprehension and memory: In Reggio documentation, photographs are presented alongside narrative quotations recorded during learning events. Just'as with illustrations in storybooks, it might be that documentation has similar facilitative effects. 


\section{CHAPTER V}

\section{EXPERIMENTAL HYPOTHESES}

The current study extends past research in several ways. First, it provides quantitative data concerning the effects that documentation has on young children's memory. Current educational literature offers speculative claims and qualitative research but has yet to take an experimental appròach towards understanding these effects.

Second, the current study contributes to the growing understanding of how children are able to use photographs to reinstate memory, exploring whether their usefulness extends into an educational context. Third, this study extends past research regarding the effects that conversations have on children's memory. It investigates the memory effects that direct text feedback of children's self-generated comments has, as well as the role that elaboration might play when presented in documentation (i.e. on a poster board documenting a learning event) and in the conversations that occur while reviewing documentation. The implications of documentation for two kinds of memory are examined: episodic memory, or recollection of the learning experience detailed in the documentation, and semantic memory, or content information introduced during the experience. 
The current research study worked to carefully isolate the practice of documentation in order to evaluate its effects on young children's memory. To accomplish this, groups of 4.5 to 6-year-old children experience a novel learning event. In a subsequent session ( 48 hours later) the children are either reminded of the learning event and its content information or they are not (i.e. the control group). Children are reminded either by reviewing a poster form of documentation (documentation condition) or by completing a series of related worksheets (worksheet condition). Following a threeweek delay interval children complete a memory interview about the learning event and content information. This paradigm allows for systematic measurement of the effect that documentation has on children's episodic and semantic memory as compared to the other conditions.

Based on previous developmental memory research and educators' observations, it is expected that children exposed to documentation will have greater recall of both the learning event (episodic memory) and the content information (semantic memory) than children in the worksheet and the control conditions. It is predicted that the. documentation group's advantages in memory will most clearly be seen when comparing their memory interviews to the non-reminded control group. Specifically, the documentation group should report a larger number of accurate mentions of event information and content information in free and prompted recall, as well as greater use of mentions of the self and other people across the interviews. Children in the documentation group may also show better source monitoring abilities, when prompted for the source of the knowledge they acquired during the learning event. It is further 
expected that all children will remember information they experienced directly through manipulation (e.g., related to props they held) better than information they experienced

indirectly (e.g., related to props that other children held), and this effect may be exaggerated for children in the documentation condition. Finally, it is expected that children will remember sub-facts they were reminded of during the dòcumentation or worksheet conditions in session two better than sub-facts that they were not reminded of. 


\section{CHAPTER VI}

\section{METHOD}

The literature review has outlined the many positive claims made by Reggio Emilia educators regarding the effects that documentation has on children's learning and memory. The review has also provided theoretical support for these claims which is based in developmental and educational theory. However, to date no qualitative research has been conducted to evaluate documentation's effects on young children's memory. The present study examines the effects that the practice of documentation has on children's memory of educational material presented in an early childhood education classroom setting. The study focuses on two aspects of memory, episodic or "event" memory and semantic or "content information" memory.

\section{Participants}

The participants included 66 children/attending five suburban New England early childhood education centers, referred to henceforth as "schools." Three children did not complete the research protocol resulting in 63 total participants. Participants were recruited through letters sent home to parents. Parents completed parental consent forms prior to their child's participation. The consent form described the study and requested signed consent for each participating child. 
Background information regarding each of the five schools was found on their respective web pages. Based on their teaching philosophies, the following characteristics: exist among the schools. Three schools place value in child directed activities and four schools value rich experiences and exploration. Though not the same two schools, two of the five follow social constructivist theory, place value in family and/or culture, and have an emergent/responsive curriculum. It is also noteworthy that two of the five schools specifically follow the Reggio Emilia approach to early childhood education. Additional information regarding each school, including the programs offered, the number of children and staff, and the school's National Association of Education for Young Children (NACEY) accreditation status can be found in Table 1. 


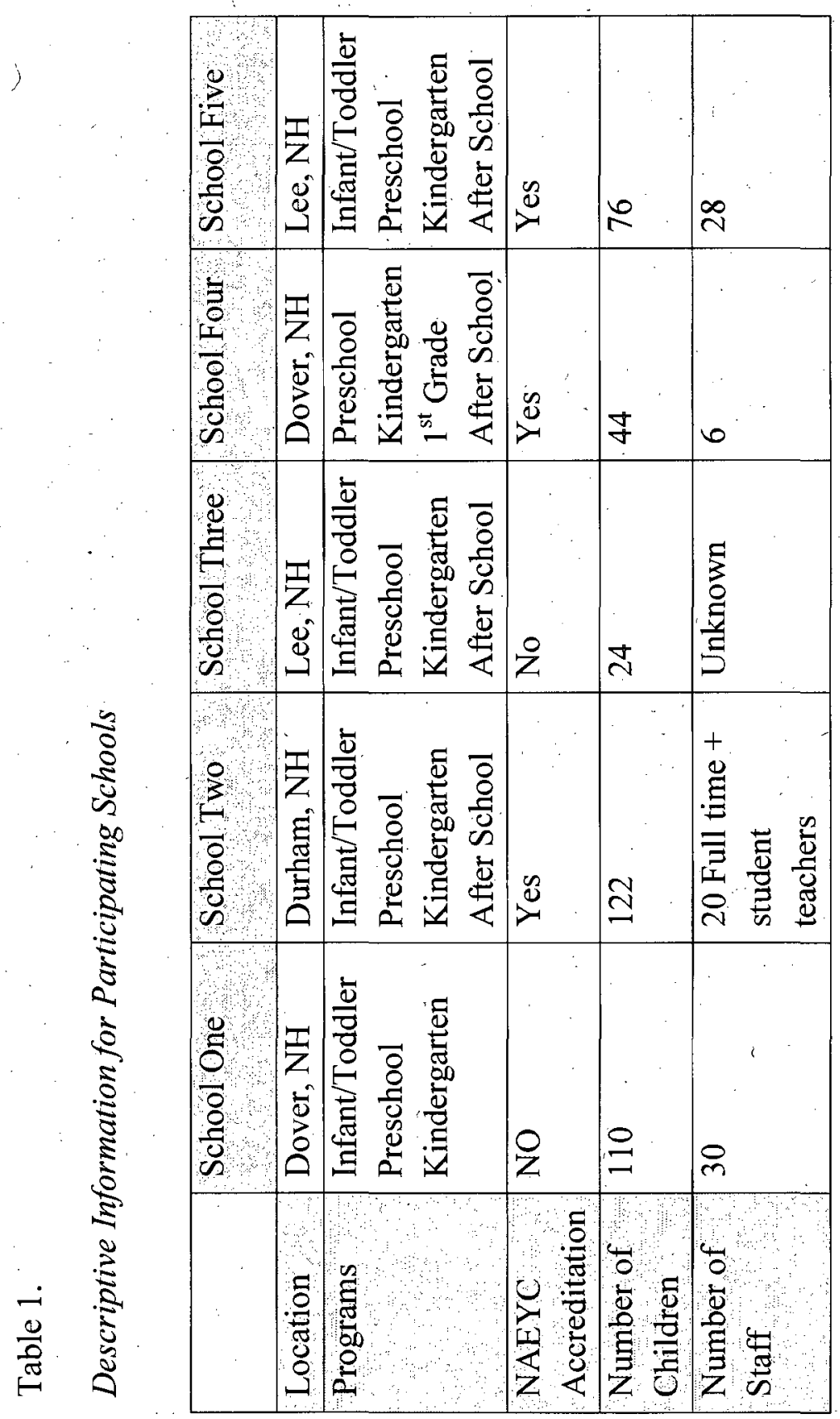

m 
Thirty-one male and 32 female children participated. Participants ranged in age from 45 to 77 months with an average age of 60.92 months $(\mathrm{SD}=6.88)$. This is equivalent to 5.07 years (the mode was 57 months or 4.75 years). A total of 25 children were enrolled in preschool classrooms while the remaining 38 were enrolled in kindergarten classrooms. The total number of children from each center broken down by gender and average age is presented in Table 2. 
Table 2.

Participants' Demographic Information: Frequencies \&. Mean

Age

School One

School Two

School Three

School Four School Five

Male Preschool

4

4

0

3

1

Female Preschool 3

7

0

3

0

Male Kindergarten 1

8

2

3

5

Female Kindergarten 3

9

2

1

$\frac{4}{\text { Total }}$

10

Mean Age

11

28

4

10

59.5

60.09

$63: 39$

52.25

59.80

$\mathrm{SD}=5.16$

$\mathrm{SD}=7.05$

$\mathrm{SD}=7.13$

$\mathrm{SD}=5.15$

$\underline{\mathrm{SD}=6.86}$. 


\section{Procedure for the Early Childhood Environment Rating Scale Revised (ECERS-R)}

After obtaining consent from each school, two researchers conducted an observation of all classrooms from which participants were recruited. These observations served two functions. First, the observations worked to familiarize the children with the researchers. By having the researchers present in the classroom prior to the main study children became more comfortable with them and less apprehensive about participating in later experimental sessions. Second, during the observation visit the two researchers completed a portion of the Early Childhood Environment Rating Scale, Revised Edition 2005. The ECERS-R is a widely accepted tool used to measure the quality of early childhood programs. It is designed for use in preschool, kindergarten and child care classrooms serving children 2.5 to 5 years old. In total the instrument consists of 43 items on a 7 point scale with indicators for inadequate, minimal, good and excellent. The scale was used in the present study to provide background information regarding the classroom environment of the participants (Harms, Clifford, \& Cryer, 2005).

Specifically; the ECERS-R is composed of 7 sub-scales titled as follows: Space and Furnishings, Personal Care Routines, Language-Reasoning, Activities, Interaction, Program Structure, and Parents and Staff. Overall the entire scale has high reliability at the sub-scale and individual item level. Interater reliability among trained observers on the individual item level are all reported above an agreement level of $70 \%$. Product moment correlations (Pearson values) between observers are reported at .921 and .965 for rank-order (Spearman values) (Harms et al., 2005). 
Researchers Perlman, Zellman, and Le (2004) evaluated the psychometric properties of the scale using 202 Colorado area childcare centers. They found that the ECERS-R measures one global aspect of quality rather than seven distinct aspects as its subscales would suggest. Because various subsets of items (which the authors randomly and systematically chose) were comparable to overall quality scores when using the full version, it is suggested that shorter versions can be utilized for all subscales. Furthermore, after running the ECERS-R items in an oblique factor analysis using the Kaiser criterion (i.e., eigenvalues greater than 1.0) to determine how many distinct aspects of quality were actually being measured it was found that 71 percent of the total variance was explained by the grouping of items in the subscales related to Child Activities, Program Structure, and Space and Furnishings. Ten percent of the variance was accounted for by items including staff-child interactions such as personal care routines and language development. The final factor identified explained 6 percent of the variance and included items about provisions for parents and staff (Perlman et al., 2004). Based on these findings, and because this tool is being used as a descriptive measure of the classroom environments of the participants in this study, we only completed the four most relevant of the seven subscales during our observations. The four subscales. we used included Space and Furnishings, Language-Reasoning, Activities, and Program Structure. This provided us with an individual score on each subscale and an overall average of these four subscales (but only a proxy for the score of the entire classroom quality).

Prior to completing the ECERS-R both researchers were trained using the video training procedure provided for the ECERS-R (Harms \& Cryer, 1999; Harms \& Cryer, 1999). The researchers then practiced the scale multiple times using toddler and 
preschool classrooms in a local childcare facility. These classrooms did not participate in the rest of the study. Furthermore, the primary researcher received advice and instruction from a faculty member in the Education Department at the University of New Hampshire who has extensive experience with the scale. During the observation period the two researchers completed the scale simultaneously and independently while observing each classroom for at least two hours. After the observation the researchers met to compare their results and came to a unified decision regarding any disagreements. To check for inter-rater reliability nonparametric Spearman correlations were computed for ECERS-R subscale scores for 3 of the 8 classrooms (37.5 percent of the data). Spearman correlations were very strong, $\mathrm{r}=1.00(3), p<.001$ (two tailed). The total subscale score for all classrooms on the four subscales is presented in the results section under the ECERS-R results label.

\section{Experimental Procedure}

Following the observation period, the actual experimental procedure took place in three sessions. Session one and session two were separated by 48 hours while session three occurred three weeks later. To ensure that the delay interval between sessions one and two remained consistent across groups, the time of day that each session took place was the same. For example, if session one occurred during the morning (when children were usually engaged in work-related activities) session two also occurred in the morning.

Children participated with a researcher in session one in groups comprised of six children each, in session two in groups comprised of two children each, and in session three individually. In session one, all groups experienced the same procedure, while in 
session two the procedure varied between groups according to experimental condition. Two children from each group of six at session one was assigned to each of the three experimental conditions in session two. This worked to ensure that any differences between the conditions were not a result of inadvertent differences between groups at session one.

During session one groups met in a separate room in the school, apart from their classroom. Children were randomly assigned to their six-person session one group from the pool of all participating children from their school (regardless of which classroom they were in). To assign each child to their group of six, three female names and three male names were drawn at random from envelopes to approximate gender balance. In some cases there were not three children of each gender available resulting in some unbalanced groups. During session two, each group of two children was randomly assigned to one of three experimental conditions. Random assignment was completed again by pulling children's names from an envelope. In sum, from each school groups of six children each were produced. In session two the six children were broken in to groups of two children, with each group representing one of the three experimental conditions. The final session involved each participant meeting individually with a researcher. See Figure 1 for a visual depiction of the number of participants in each experimental session. 
Figure 1.

Participant Break Down Through Experimental Sessions

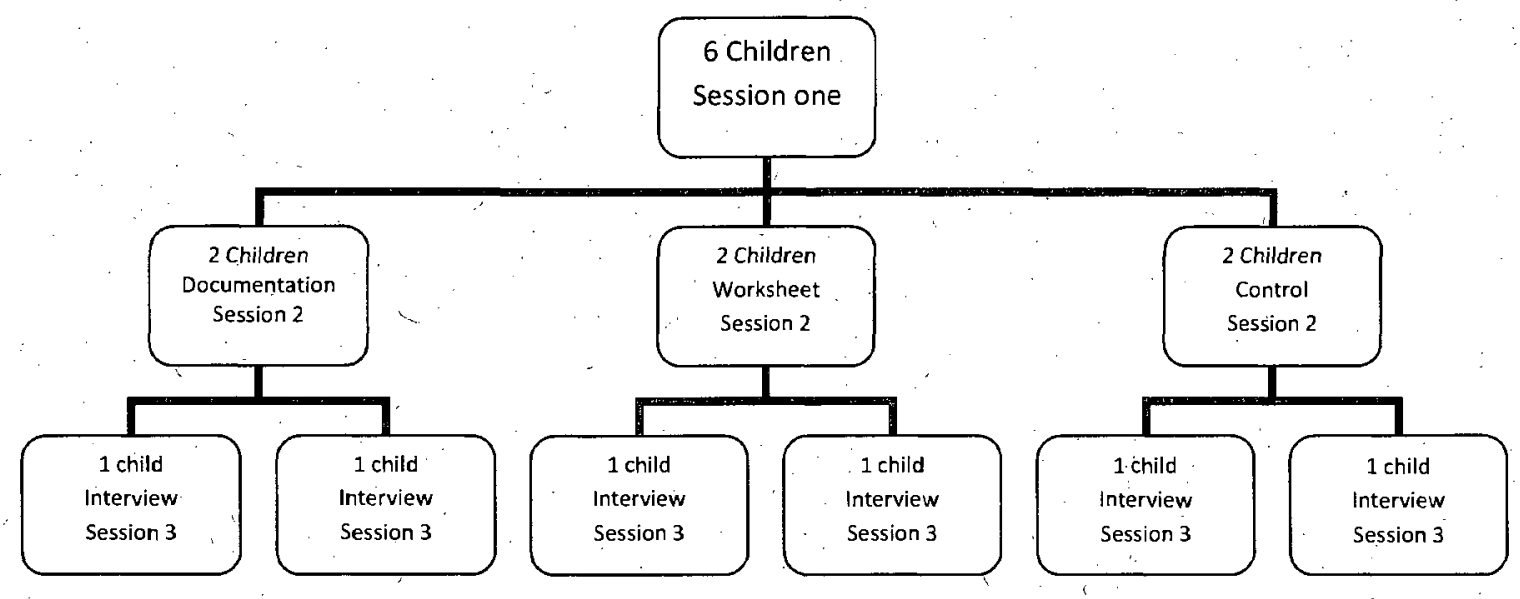


The following section describes in full detail the procedure in each of the three experimental sessions.

\section{Session One:}

In session one each group of six children met with a researcher to participate in a learning activity. All groups of children participated in session one in exactly the same format. The learning activity presented the children with educational material about the country of Panama, located in Central America. The reason that the content of session one is about the country of Panama is because it is a topic that is novel to most children living in the United States, yet children have background knowledge that they can apply from their experiences here in this country. For example, children might not know what special holidays people in Panama use the Panama flag for, however many of them have seen the U.S. flag used in their homes, schools and communities.

The learning activity itself was designed in such a way that it modeled some major principles of the Reggio Emilio approach to early childhood education. For example, the activity was a cooperative exchange between the children and the researcher. Together, the children and the researcher explored the topic of Panama by first talking about information children already knew about related concepts (i.e., what a country is and what they know about the country they live in). Children were invited to share their thoughts, feelings and reactions and then tálked about new information specific to Panama. While the information was being learned, the children's input was often asked for and valued so that the learning activity was one to which the children contributed significantly. Children were also able to touch and manipulate objects, 
providing them the opportunity for a hands-on, attention sustaining learning environment. The entire learning event was videotaped and photographed by an undergraduate research assistant.

The educational material presented consisted of three main facts about Panama. Each main fact had three sub-facts which were related to the main fact. The activity began with a short introduction in which the researcher used a seript (while still pausing, listening, and validating children's responses in a friendly, encouraging manner whenever they arose). The researcher then pointed the children's attention to a $5 \times 7$ map of Panama that was on the cover of a large, decorated, plastic box. The children were allowed to point and touch the map as they wished.

Following the introduction the children and the researcher worked together to learn new information about Panama, including the three main facts and their three related sub-facts. The researcher then opened the decorated box. Inside the box were six items, each related to one of the three main facts. The items included two Flags of Panama, two plastic toy Harpy Eagles, and two models of native guitars. Attached to the eagle and guitar props were small realistic pictures of what those objects look like. Two at a time, the children were encouraged to pull the duplicated items out of the box. For example, two children each pulled out the flags of Panama. As the items were taken out the researcher used a script. (See Appendix A for a full script of session one.) A portion of the script is presented below as an example. 


\section{Main Fact: What the Panama flag looks like}

Prop from box: 2 Panama Flags

Researcher: "What did you pull out from the box? You're right it is a flag, the flag of Panama! What are some things you notice about the flag of Panama? What are the colors on the flag? What are the shapes on the flag?

\section{Sub-fact A: What the star's colors sỳmbolize}

Researcher: "What shape is this on the flag (point to stars)? Are there other flags that have stars? Aren't the colors on the flag wonderful! What colors are the stars? Did you know shapes and colors can mean different things? The blue star on the flag means honesty (telling the truth) and the red star on the flag means laws (following the rules) (Panama -'Flag, 2005)".

\section{Sub-fact B: The age of the flag}

Researcher: "You know the flag of Panama is very old too! How old are you? The Flag is much older than that. The Panama flag was made by the first president ever in Panama in 1904. That makes it 104 years old! (Panama - Flag, 2005)."

\section{Sub-fact C: The flag is used in the Carnival celebration}

Researcher: "What do people use flags for? Where do you see flags? People in Panama use their flag in special parades on a holiday called Carnival. Carnival is a 2 day celebration with parades, singing, dancing and lots of great food (Carnival, 2005)."

After all the main facts and sub-facts had been discussed the researcher concluded session one. The researcher asked the children to put each item back in the box and took a minute to thank the children for sharing and learning all about Panama with her. 
Session Two:

Session two occurs 48 hours after session one. In session two, groups of two children meet with the same researcher as in session one. Session two proceeded in two parts. The first part was a reminder task which aimed to remind the children of the learning activity and/or the learned content from session one and was ten minutes long. The procedure for the reminder task varied based on the experimental condition that the child was assigned to. The second part was the presentation of additional new information about Panama and was five minutes long. It was the same for all children. Children in all conditions were video recorded throughout session two.

Part One, The Reminder Task: Children in the Documentation Condition met with the researcher and participated in a reminder task in which they were exposed to Reggio style documentation. The documentation took the form of a poster board (made by the researcher). It included photographs and dialogue which were taken during session one of the experiment. For example, on the documentation there were pictures of each child holding an object related to the lesson and a quotation, beside it from the child describing an idea related to the topic or object. Together the children and the researcher reviewed the documentation. While reviewing the documentation the researcher paused to allow children time to talk, ask questions, and elaborate when desired. The reminder task was ten minutes long and the researcher made sure to read aloud and draw the children's attention to every aspect of the poster. 
The goal of the documentation was to remind the children of factual content information from session one as well as information about the actual learning event. (A model of a documentation poster can be found in Figure 2 and will help in understanding the following description). The documentation poster was entitled "Exploring Panama." Next to the title was a photograph of the whole group taken during session one and small narrative paragraph. After reading the paragraph to the children the researcher read systematically through the rest of the poster with the children. After each portion of the poster was read, the researcher paused to allow children to contribute to the conversation: Under the narrative paragraph the poster was broken into three columns, one for each main fact. Pictures of the main fact and two of the sub-facts were displayed in each column as well as photographs of each individual child when they were holding a related prop. All together this created a poster in which all the children saw one individual photograph of themselves while holding the main fact prop that they pulled out of the box. Alongside each photograph was a quotation taken from the child stating something that they said related to the object during the learning activity. For example a quotation might say "I like these colors," "this is a big bird," or "my dad has a guitar!" Below the 2 photographs in each column two of the three sub-facts that related to the main fact were stated. The two sub facts that were presented remained constant across the documentation and worksheet conditions. 
Figure 2.

Documentation Poster

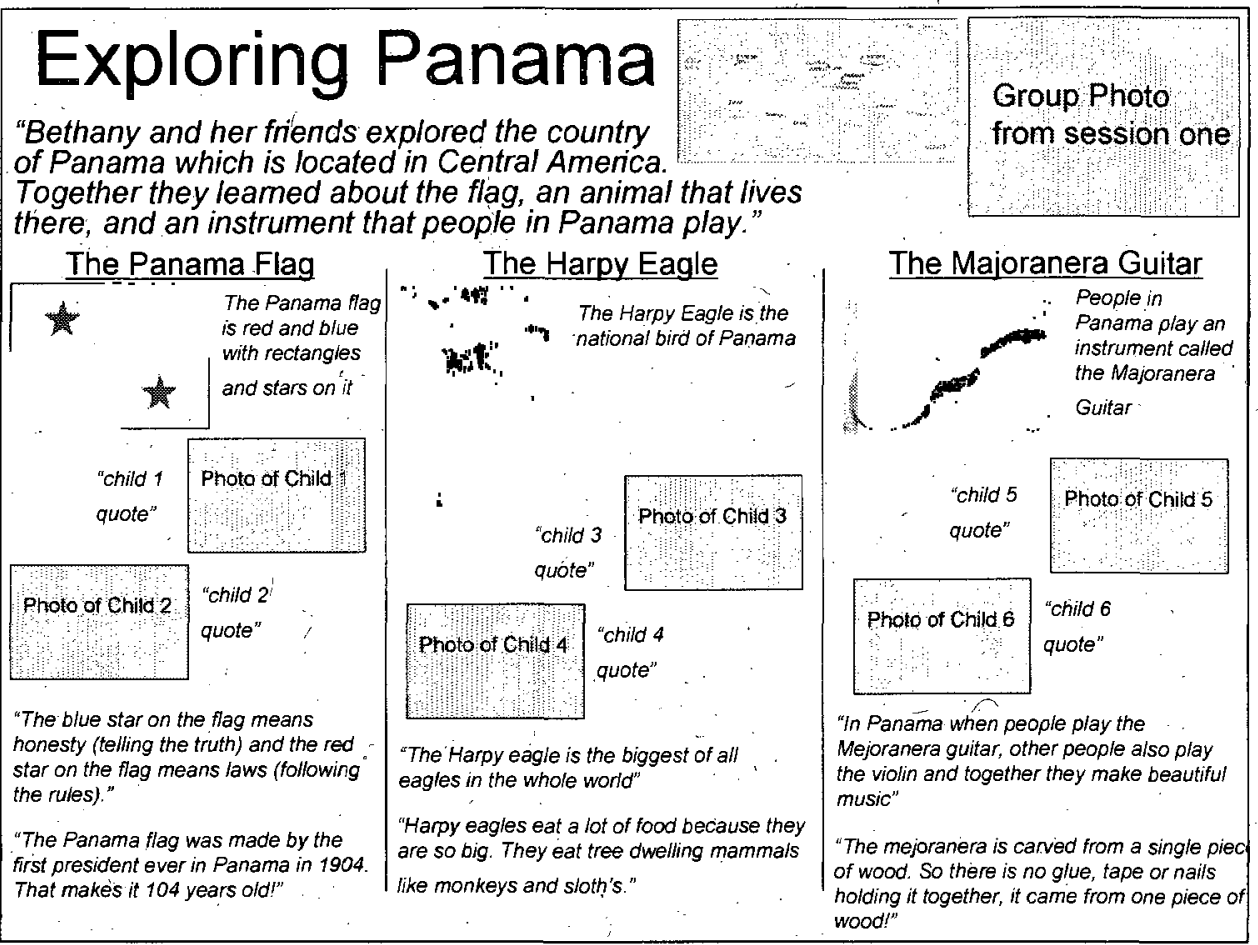


Children in the Worksheet Condition also met with the same reséarcher but they participated in a reminder task using worksheets similar to those often used in more traditional North American education systems. In this condition the reminder task consisted of small and simple activities that were completed on two, one-sided worksheets. For example, an activity on the worksheet asked children to color in a star which they learned about during session one. (A model of both worksheets can be found in Figures 3 and 4.) 
Figure 3.

Worksheet One

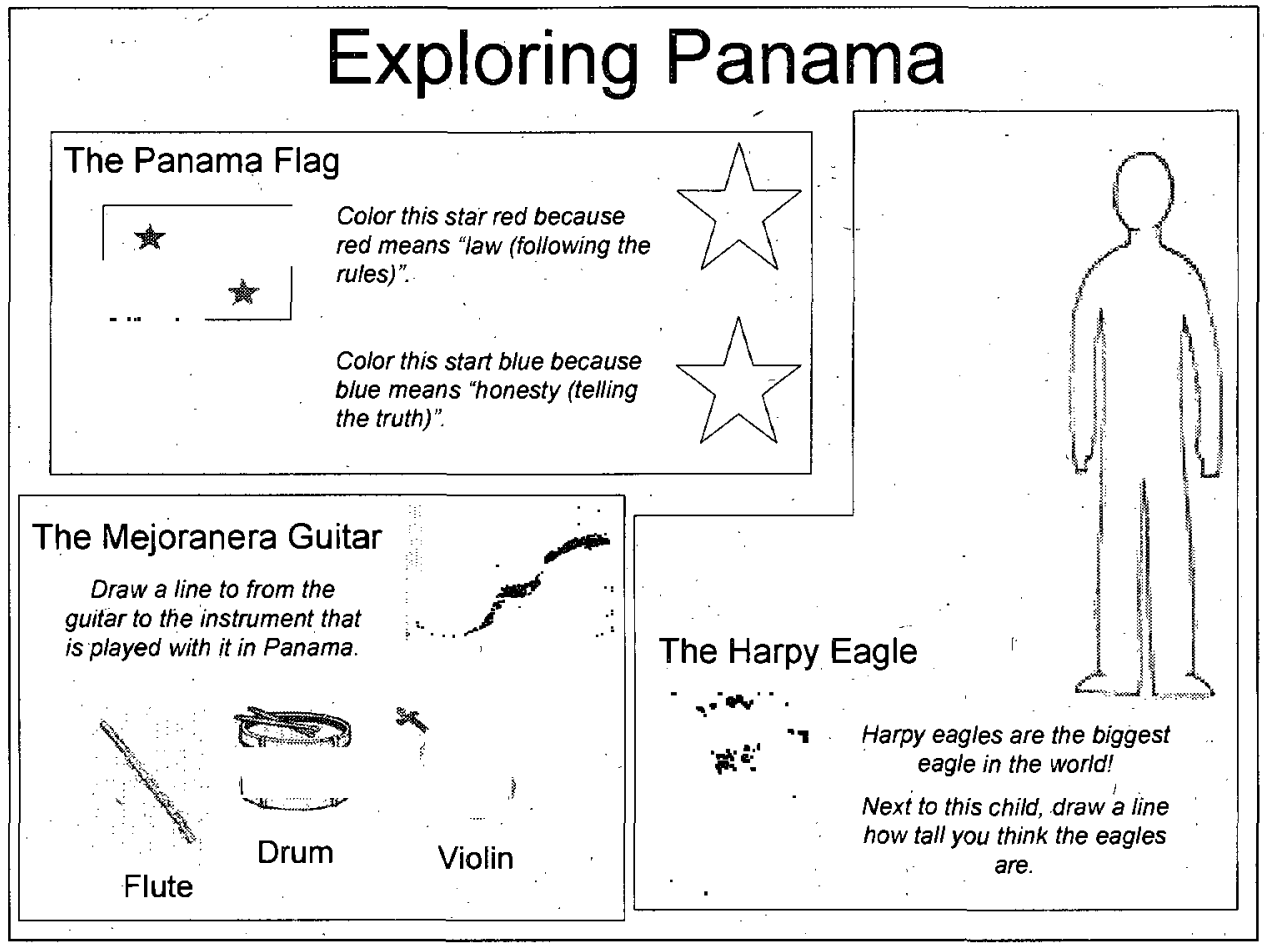


Figure 4

Worksheet Two

\section{Exploring Panama}

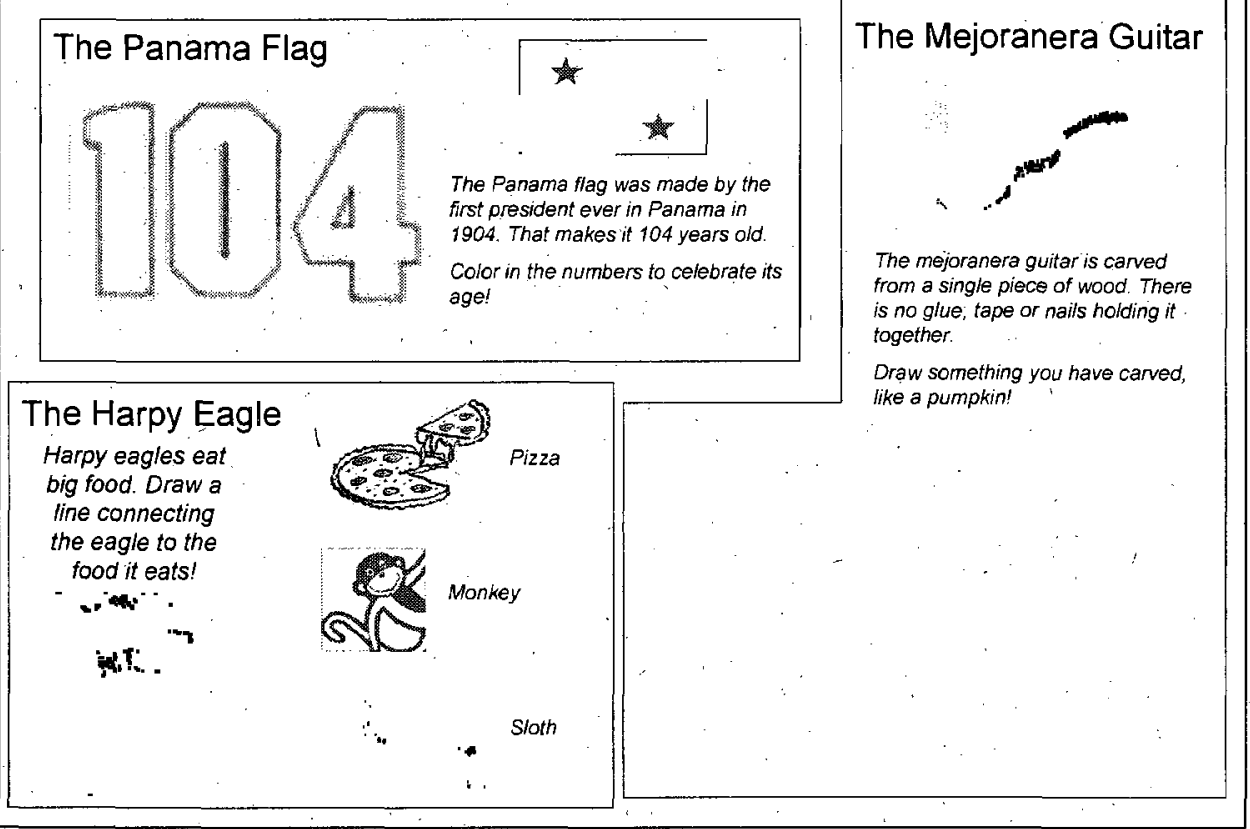


During the worksheet condition the researcher read a script that lead children through the activities on the sheet. The worksheet was developed in such a way that it provided the children with factual reminders about the information learned during the learning activity in session one but did not explicitly remind them of the learning activity itself. The researcher read the directions and all additional text on each worksheet to the children as they worked on it so that the children knew exactly what each activity was. The worksheet took the researcher and the children ten minutes to complete.

Just as with the documentation condition, the worksheets reminded the children of each main fact as well as two of its three sub-facts from the original learning activity in session one. The same sub-facts were presented in this condition as in the documentation condition. The worksheet was broken into thirds, one section for each main fact and an activity based on the main fact's related sub-fact. The sub-facts that the children received on the worksheet were exactly the same for all children in the worksheet condition.

The last condition is the No Reminder Control Condition. In this condition children were given no reminder of information or the event from session one. However, they did still meet with the researcher and complete unrelated worksheets about fire safety called "Exploring Fire Safety". The worksheet took ten minutes to complete and consisted of activities that were set up in a similar way as the worksheets in the worksheet condition. Just as in the worksheet condition, the control worksheet is broken into three columns each with its own activity to complete: A sample of the control worksheets can be found in Figures 5 and 6. 
Figure 5.

Control Worksheet One

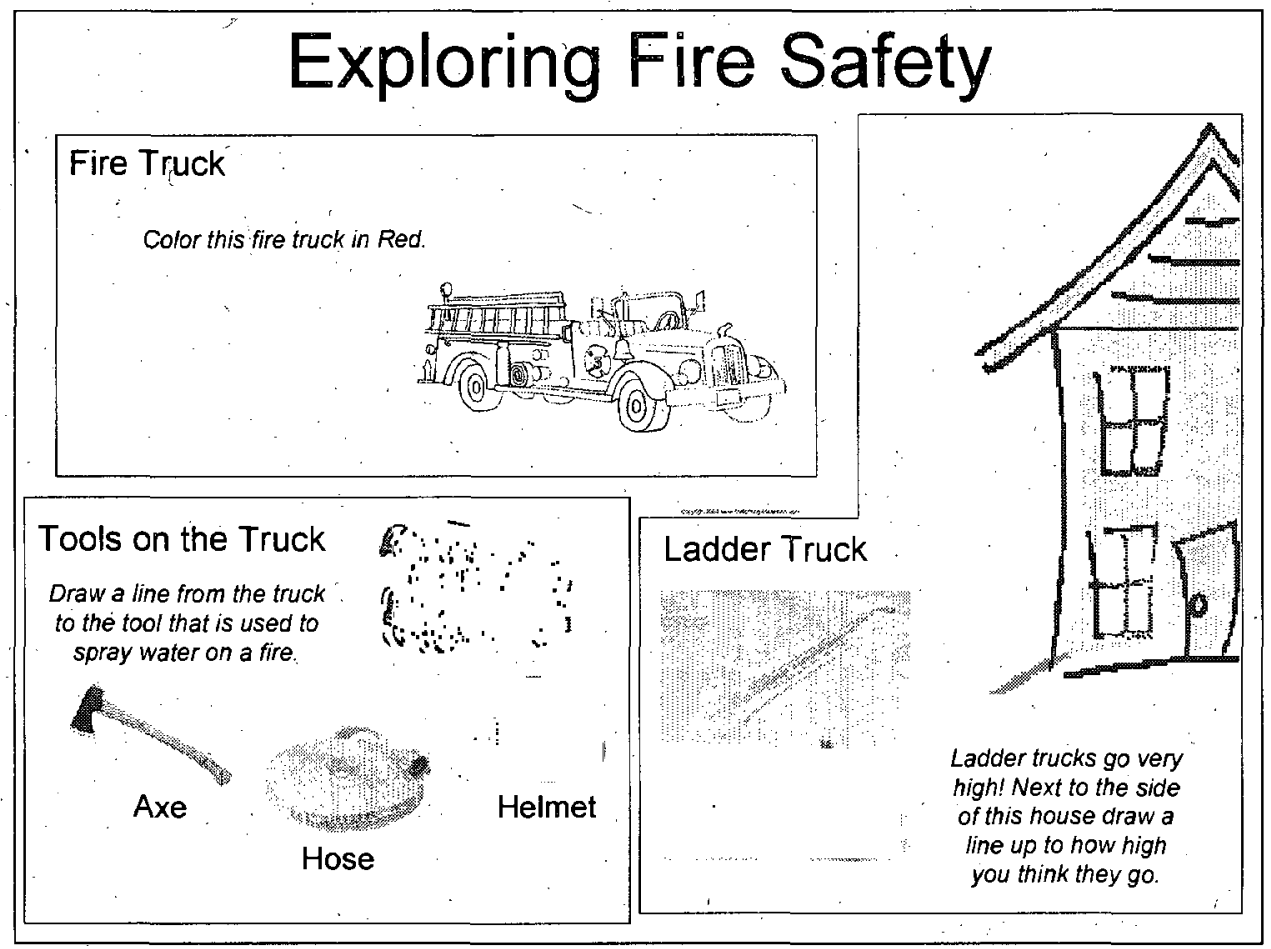


Figure 6.

Control Worksheet Two

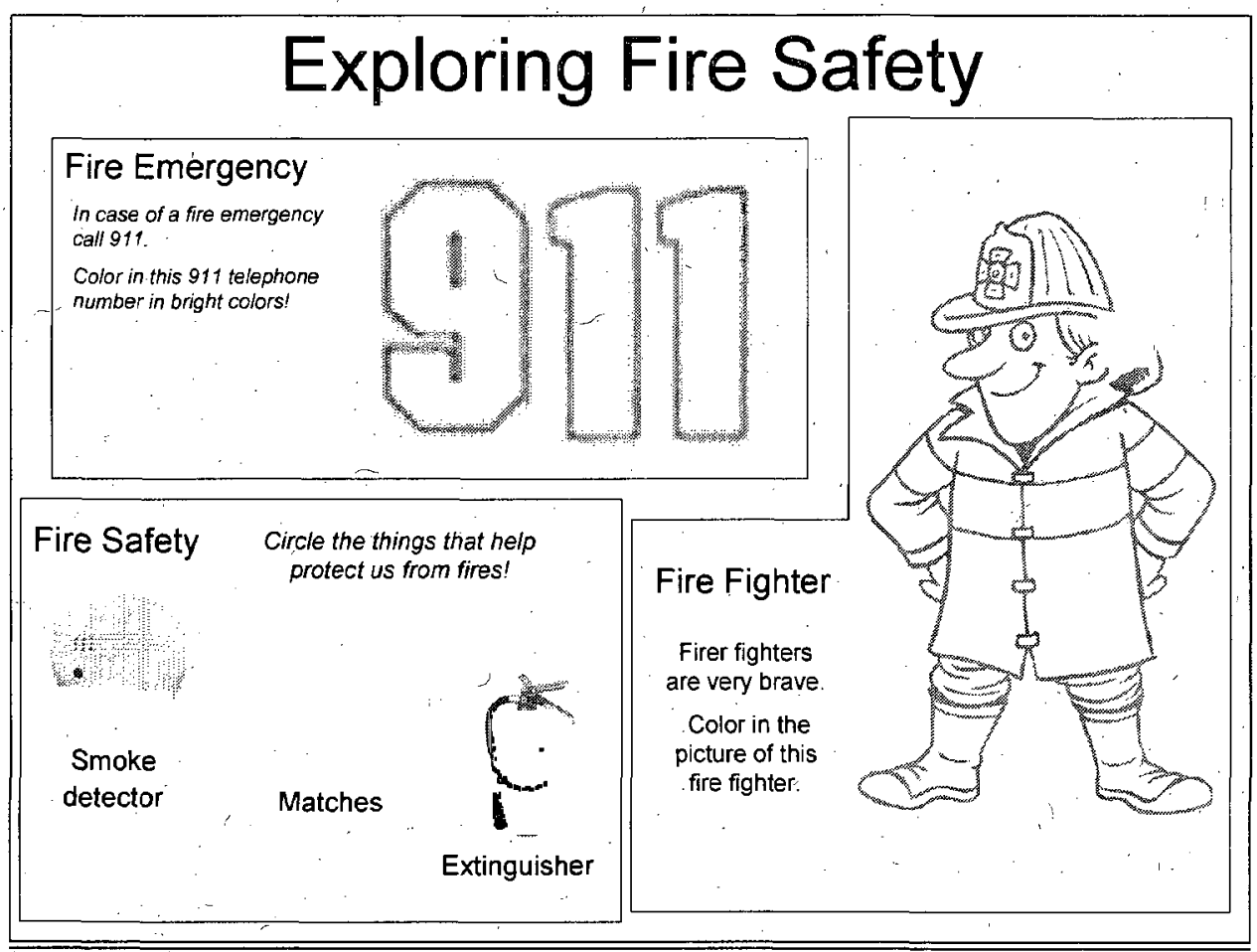


Part Two: Presentation of New Information: The second part of session two is the presentation of new information. All groups of children received the same new information during this part of the session, presented in the same way. The researcher told the children they were going to learn two new things about Panama. The reason for presenting the children with new information is because it allowed us to investigate if documentation aids children in the acquisition of new knowledge as the learning event is extended. This also provides an ongoing learning experience which is more closely tied to the naturalistic occurrences in the Reggio approach:-

The new learning experience modeled the procedure from session one; however, instead of the children selecting objects from the box the researcher took objects out from under the table and placed them on the table for the children to each take a turn holding. The objects that the researcher presented to the children included a picture of the Panama canal connected to a plastic toy boat, a map of Panama and a small figurine of a businessman with an attached picture of the real Panama president. As the new objects were shown to the children two new main facts were presented using a detailed script. (A full version of the script used in session two for all conditions can be found in Appendix C.) After the two new main facts have been discussed the researcher concluded session two. The researcher asked the children to give the objects back and thanked the children for sharing and learning all about Panama with her again.

\section{Session Three:}

Session three was the final session of the research protocol. It took place three weeks after the completion of session two and was an assessment session in which the 
children's memory of the learning activity and their memory of the content learned was measured. The memory interview took approximately 25 minutes to complete. During this session children met individually in a quiet, separate room in their school with a new researcher and completed a video-recorded memory interview. The new researcher was an undergraduate research assistant who was blind to the hypothesis and experimental conditions in the study. The research assistant was extensively trained in the interview process and practiced on numerous children before collecting any data. During the memory interview the researcher read each question from a script. The script was also used as a score card where the interviewer was able to make note of certain aspects of the children's responses as the interview progressed.

Specifically the memory interview consisted of event questions, open ended factual questions, word recognition questions, open-ended and prompted questions about specific facts, recognition questions, and source monitoring questions. The event questions were the first questions that children were asked. These questions asked children to remember events that occurred during the learning event in sessions one and two. These questions were specifically designed to tap into children's episodic memory. For example, one event question in the interview read, "I heard that you met with my friend Bethany two times and that you learned about the country of Panama. I wasn't there those times, but I'm interested in all the things you did when you met with Bethany and learned about Panama. What can you tell me about that?"

The second set of questions consisted of open-ended factual questions. These questions asked children what factual information they remembered from session one and 
two. An example of a factual question is, "Now I'm interested in finding out everything that you know about the country of Panama. What are some of the things that you can tell me about the country of Panama?" The third set of questions consisted of word recognition questions. These questions gave children the chance to recognize if they had learned about a mentioned item instead of recalling the item in an open-ended format. These questions were intended to tap into children's factual knowledge or semantic' memory concerning Panama. The item recognition questions were presented to children in the following way; "I am going to name some things that you might have learned about those times you met with Bethany. You can say "yes" if you learned about the thing and "no" if you didn't. For example, did you learn about a swimming pool with Bethany? No, you didn't. So if I say swimming pool, you would say no. Okay, so, those times you met with Bethany, did you learn about a dog? Yes or No?"

The fourth set of questions that children were asked questions about specific facts. These questions tapped into children's semantic memory and were about the specific knowledge that children learned regarding Panama (the three sub-facts under each main fact). There were three parts to each specific fact question. A broad open-ended question was asked first to see if children recalled information regarding each of the facts they learned about. A second open-ended question was then asked which was more focused on each of the specific sub-facts. After children had the chance to recall the information, they were then asked prompted/forced choice questions. These questions gave children two answers to pick from and in this way allowed children to recognize correct information. An example of this series of questions about the Panama flag is "Please tell me everything you know about the Panama flag. (open-ended). The stars on the Panama 
flag mean something. What do they mean? (open-ended). Now I'll give you two choices: Do the stars on the flag mean "happiness and sadness" or "honesty and laws? (forced choice)!"

The fifth set of questions in the memory interview was comprised of photograph recognition questions. The child was presented with four photographs. Three of the photographs were conceptually related to the main fact but depicted things that the child had not seen during session one or two, while one photograph depicted an item the child had seen. The child was asked to pick the one photograph they had seen and remembered learning about. After completing the recognition questions the children were asked source monitoring questions which were the last section of the interview. The source monitoring questions aimed to understand how well children identified where the information they were remembering came from. Specifically, would they claim to know the information because they learned it during session one or session two? For example, a source monitoring question read as follows, "You met with Bethany two times to learn about Panama. The first time was with a big group of children, and the second time was just with Bethany and maybe one other child. Now I want to you think really hard and tell me which time you learned about the things I'm going to name. Which time did you learn about the Harpy Eagle that lives in Panama? The first time, with a big group of children or the second time?"

After the memory interview was complete the children were thanked for their participation and were walked back to their classroom. (See Appendix C. for a complete 
transcript of the memory interview in the script/score card version that was used during the interviews).

\section{Coding}

The memory interviews from session two were coded using two separate procedures. The first procedure extracted information from the script/scorecard notes taken during the interview. The second procedure extracted information from transcriptions of certain open-ended questions. Both coding procedures were completed by an undergraduate research assistant who was not present during the learning sessions or the interviews. The research assistant coder was blind to the hypotheses and conditions of the study. The primary researcher extensively trained the coder in coding procedures for all variables prior to actual data coding. Training included many practice rounds in which the assistants' coding was compared to the primary researchers'. Each coding procedure is fully described in the following sections.

\section{Scorecard Coding:}

During the memory interview the interviewer completed a scorecard which was part of the memory interview script (see Appendix C.). This allowed for immediate recording of certain information from particular questions. For example, after asking the question "I heard that Bethany gave children some things to hold. Can you tell me some things that children held?" the interviewer immediately checked off on a list if the child mentioned the flag, eagle, guitar, boat, man/person, or map. Another example during the open ended and prompted questions about specific facts asked children "how old is that Panama flag? Now I will give you two choices, is it 104 years old or 650 years old?" 
Following that question the researcher checked off if the child answered 104 years old, 650 years old or any other possible answer.

Each scorecard was then used to complete a summary scorecard (see Appendix D for a full version). The summary scorecard was completed by the assistant coder and worked to extract and organize the information taken directly from the interview. The coder entered the information into data files and double-checked all the work. The primary researcher completed the coding procedure for 25 percent of the data (16 interviews) to check for inter-rater reliability. In the case of one recognition question, the behavioral response could not be discerned clearly on 4/16 randomly selected DVD interviews; therefore 4 additional DVD interviews were randomly selected and reliabilities were calculated only on those where the behavior was clear. All Kappa coefficients were excellent, ranging from .82 to 1.0 (perfect agreement).

\section{Transcription Coding:}

A selection of questions on the memory interview did not lend themselves to immediate recording of children's answers. For example, the event questions in the beginning of the interview were open ended and general "I heard that you met with my friend Bethany two times and that you learned about the country of Panama. I wasn't there those times, but I'm interested in all the things you did when you met with Bethany and learned about Panama. What can you tell me about that?" For questions such as these, the interviewer transcribed children's answers. Transcriptions were completed by viewing the DVD video recordings taken during session three. The interviewer used a transcription template to help guide transcription. The template indicated to the 
interviewer what questions to transcribe and provided a consistent word document template for organization across all files (see Appendix D for compete transcription coding template and list of questions transcribed).

To code the transcriptions a detailed coding scheme was created. The research assistant coder was extensively trained by the primary researcher on the coding scheme. Furthermore the scheme was practiced on example transcriptions created for that purpose. All coding was completed based on each individual question, not as an entire document. The coding variables created are defined as follows:

Correct objects: A "correct object" is counted if the child mentions of one of the following objects from session one or two:

- Flag

- Eagle (Harpy)

- Guitar (Mejoranera)

- Map

- Boat

- Man.

If the child mentions one of these "correct objects" it is counted as a value of one. Each correct object is only counted one time per question even if it is mentioned multiple times.

Other correct statement: An "other correct statement" is counted if the child mentions any item/idea from an extensive list. These statements were all ideas mentioned during session one or two. The coder was to be liberal in this variable and gave children a value of one if they mentioned part of an idea on the list or was trying to convey the idea. Some of the list is reproduced below as an example. (The full list can be viewed in Appendix $\mathrm{E}$ at the end of the Transcription coding template).

Other Correct Statements list:

- Red Star

- Blue Star

- red star means rules and laws 
- blue star means honesty and truth

- Eat monkeys

- Eat sloth's

- Play in a band

- Makes music

If the child mentions one of these "other correct statements" it is counted as a value of one. Each "other correct statement" is only counted one time per question even if it is mentioned multiple times.

Incorrect object: An "incorrect object" is counted if the child mentions any object that is not on the correct object or other correct statement lists. For example, if a child mentioned a Panama baseball team it would be counted as an incorrect object because it is not on the list and is not information we are investigating. If the child mentions an "incorrect object". it is counted as a value of one. Each "incorrect object" is only counted one time per question even if it is mentioned multiple times.

Mentions of something someone else did: A "mention of something someone else did" is a verb that the child uses to describe something that was done during session one or two. The verb must be a clear reference to the past such as "She waved a flag". If the child does "mention something someone else did" it is counted as a value of one each time this occurs (even if it is the same verb used).

Mentions of something the child did: A "mention of something the child did" is a verb that the child uses to describe something that the child was doing themselves during session one or two. The verb must be a clear reference to the past such as "I waved a flag". If the child does "mention something the child did" it is counted as a value of one each time this occurs (even if it is the same verb used).

Total words: Each word is counted to obtain a word count for each question and for the entire transcription.

Upon completion of the transcription coding the research assistant coder entered all values into data files, double checking all work. The primary researcher also doublechecked work once it was entered into data files. Inter-rater reliability statistics were 
computed. The primary researcher coded 25 percent of the data and compared it to the assistant coders'. Specifically, the total values obtained across similar type questions were compared. According to Landis and Koch's (1977) interpretations of Kappa coefficient values, it was found that inter-rater reliability was at an acceptable level. Kappa coefficients ranged from .343 (fair agreement) to .99 (almost perfect agreement). The lowest value obtained, .343 , was found for the variable "mentions of something someone else did during event questions." Upon examination of this variable it was found that the coders consistently disagreed on coding the term "we" as a mention of someone else's behavior. It was decided that "we" would be a coded as a mention of something the child did and not as something someone else did. This variable was recorded to reflect the change in understanding. Recalculation of the Kappa value indicated that this change improved reliability, $\kappa=.783$ (substantial agreement). 


\title{
CHAPTER VII
}

\author{
RESULTS
}

\section{Differences between Schools}

A series of analyses was directed at evaluating potential differences between schools on demographic and memory outcome variables. (See Table 3 for a list and description of all memory outcome variables). A one-way ANOVA revealed significant differences in children's ages among the five schools $F(4,58)=5.790, p=.001$.

Specifically, children in school three $(\mathrm{M}=46.75, \mathrm{SD}=6.50)$ were younger than children in schools one $(\mathrm{M}=63.18, \mathrm{SD}=8.42)$ and two $(\mathrm{M}=63.75, \mathrm{SD}=6.94)$, but were older than children in schools four $(M=59.70, S D=4.99)$ and five $\left(M=59.50, S \hat{D}^{-6.87)}\right.$. A series of one-way ANOVAs indicated no significant differences between schools on any memory outcome variable. (Table 4 displays the average scores on memory outcomes, providing descriptive information regarding children's performance on each variable). Differences' between schools were further analyzed by comparing schools that explicitly follow the Reggio Emilia Approach to early childhood education (schools two and four) with those that do not (schools one, three, and five). This classification resulted in 38 children total who attended Reggio schools and 25 children who did not. A series of t-tests using the Bonferroni correction revealed no significant differences between schools on any memory outcome variables. 
In sum, findings indicated no differences between the five schools or between Reggio and non-Reggio schools on children's overall performance during the memory interviews. 


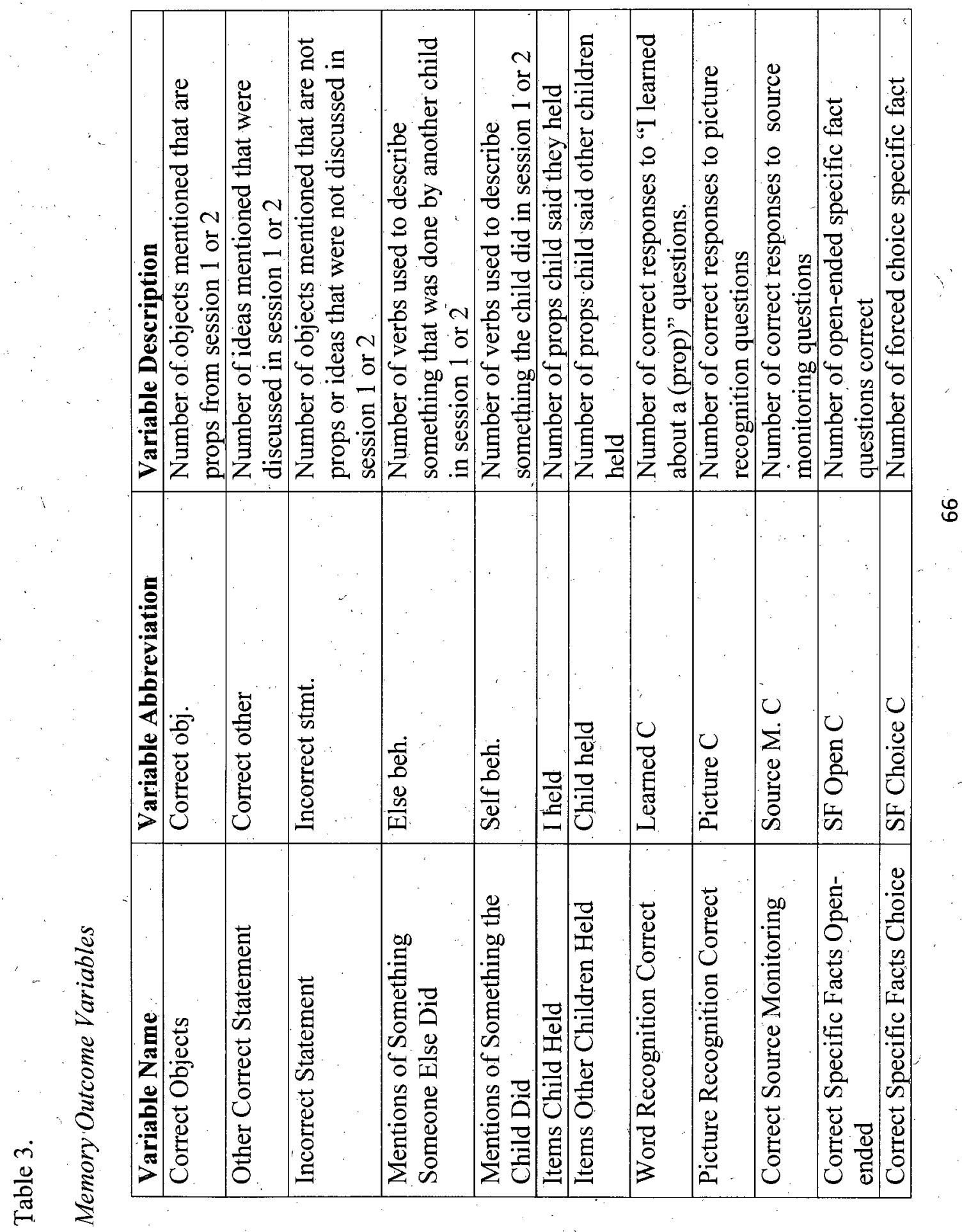




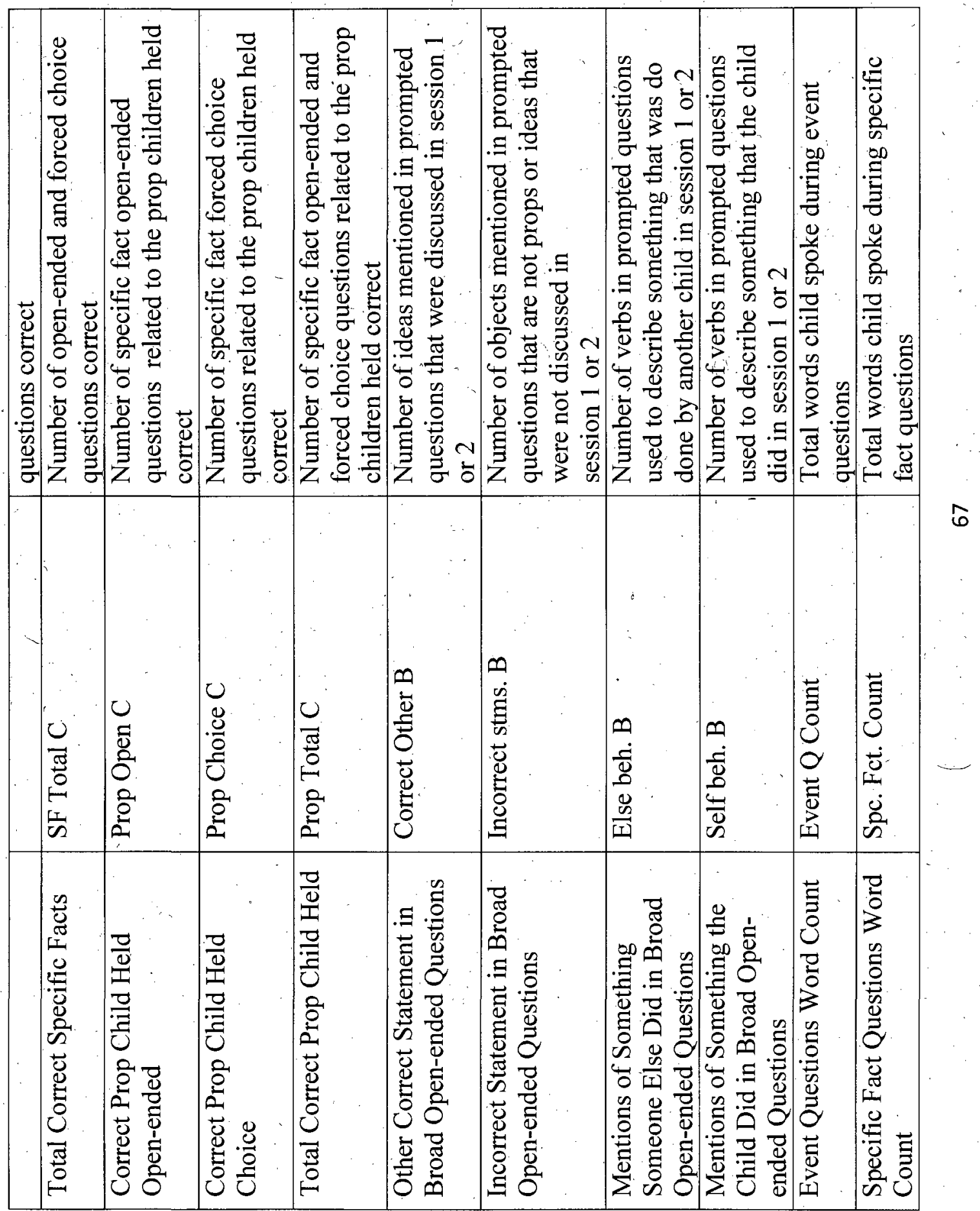




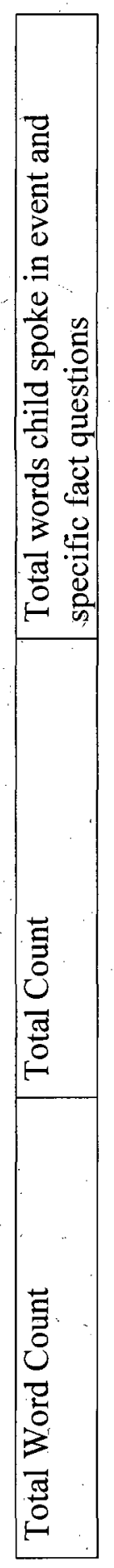




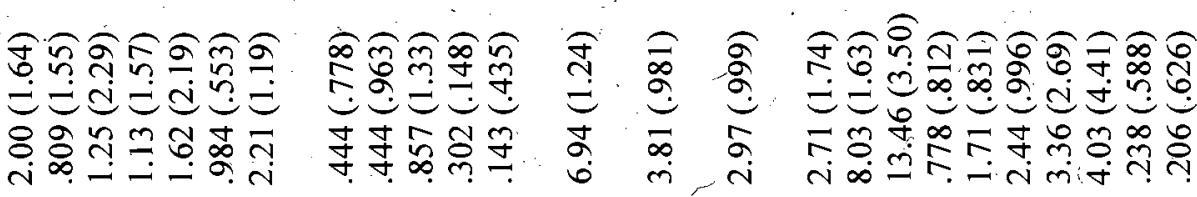

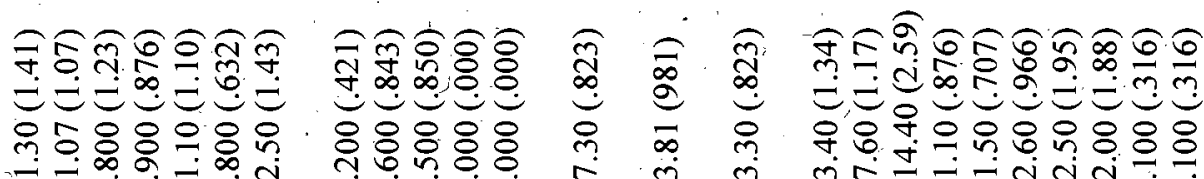

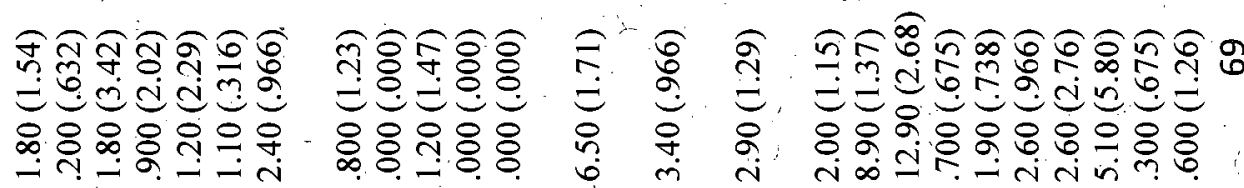

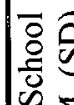

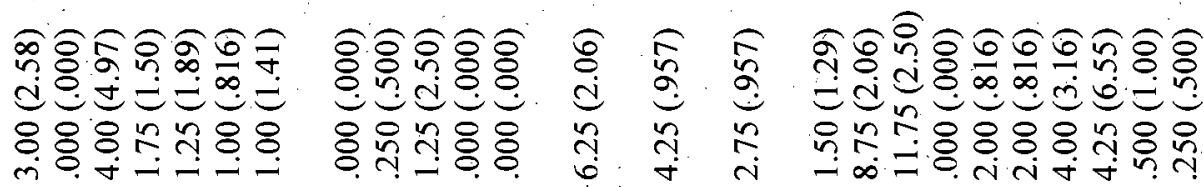

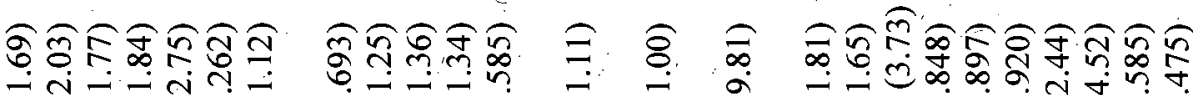

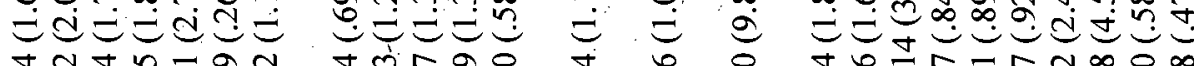

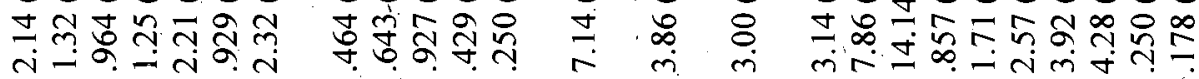

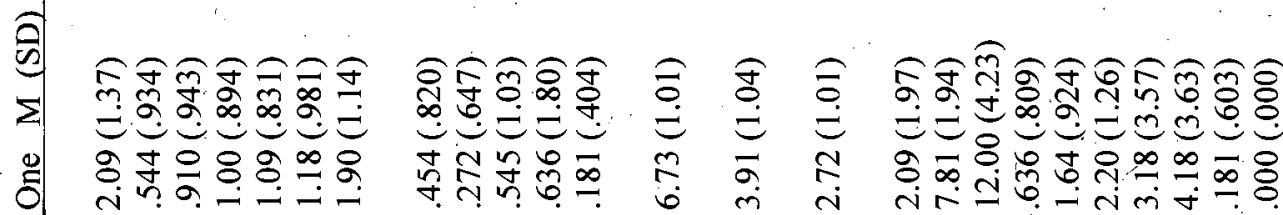

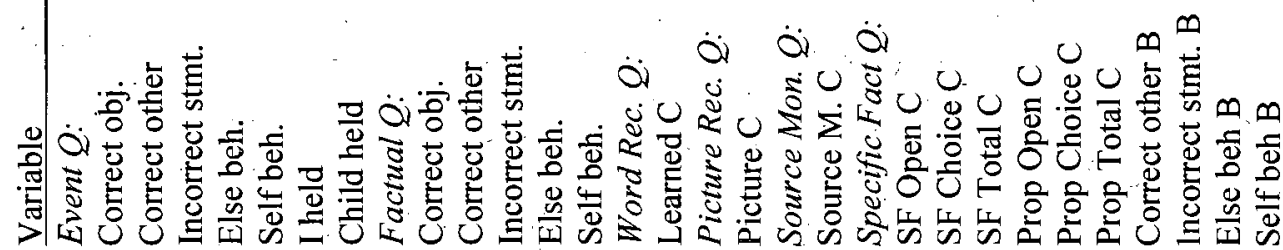




\section{ECERS-R Results}

Subscale scores and mean subscale scores from the ECERS-R are presented in Table 5. To obtain each subscale score, the scores from all items in that subscale were averaged. The mean subscale score is the four subscale scores averaged together. Each number is on a scale from one to seven. Scores of $1 \& 2$ are considered inadequate quality, scores of $3 \& 4$ are considered minimal quality, scores of $5 \& 6$ are considered good quality and a score of 7 is considered excellent quality (Harms et al., 2005). A series of one-way ANOVAs indicated no significant differences between schools for each subscale and the mean subscale scores. 


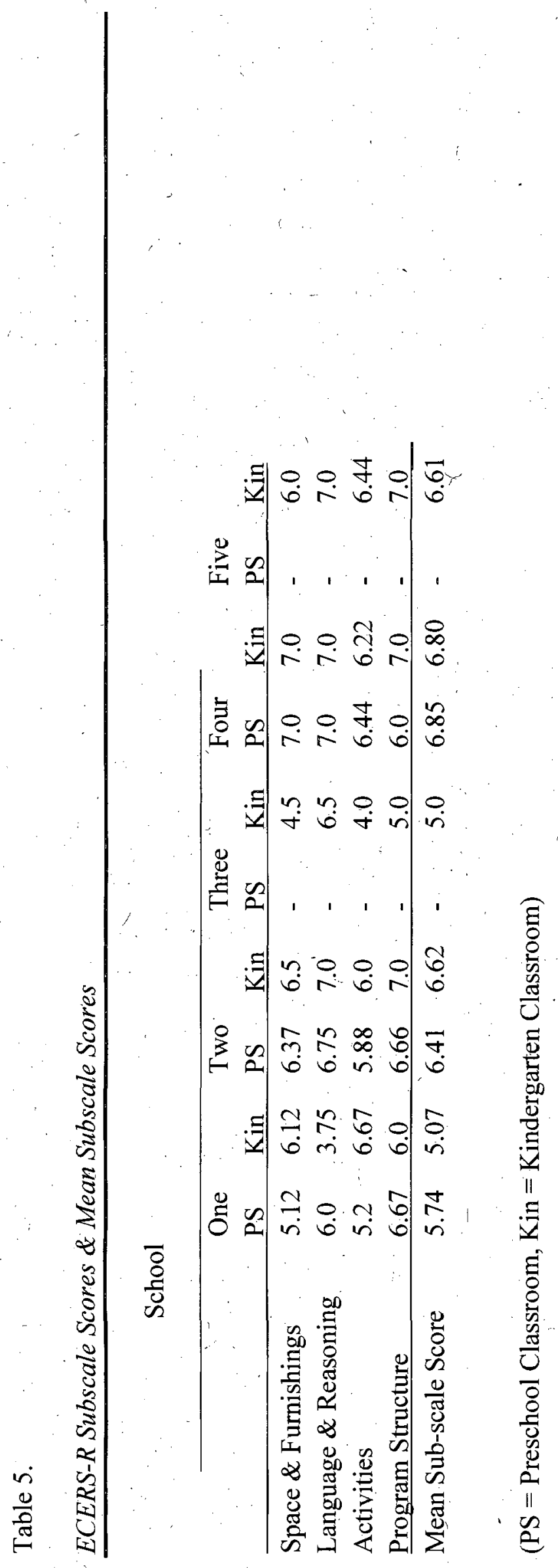




\section{Differences between Conditions}

To understand if children's memory differed based on experimental condition (documentation, worksheet, or control) a series of one-way ANOVA and two-way ANOVA tests were conducted. In the following sections, results are organized around the types of questions asked in the memory interview. For all outcome variables that summarized across more than one question (i.e., those for which one-way ANOV'À tests are not specifically reported below), a series of two-way ANOVAs was employed to investigate the effects of condition along with other potentially important variables in two models. The first model investigated condition (documentation, worksheet, control), classroom (kindergarten or preschool), and condition X.classroom effects. The second model investigated condition, gender (male or female) and condition $\mathrm{X}$ gender effects. Effects achieved in both models are reported for all outcome variables in the following section. Notably, the effects of condition (documentation, worksheet, control) were virtually identical in both two-way ANOVA models for any given outcome variable, and were identical when evaluated separately in a series of one way ANOVAs. Hence, in cases where multiple models were run, only condition effects from the first two-way ANOVA model are reported in the following sections. For all analysis Bonferroni multiple comparison post hoc tests were computed and are reported.

\section{Event Questions:}

Each of the six event questions were run independently using one-way ANOVA. tèsts to determine if differences existed based on experimental condition. All outcome variables from the coding scheme were analyzed. A significant difference was found in event question five (i.e., "What did you say?") in the amount that children mentioned 
their own behaviors in open ended responses, $F(2,60)=3.66, p=.032$. Post-hoc test revealed that children mentioned their own behaviors significantly more in the worksheet group than the documentation group $(\mathrm{p}=.038)$. The control group mean fell between the documentation and worksheet groups and did not significantly differ from either (see Table 6).

A significant difference was also found in event question six (i.e. "Can you tell me anything else that happened those times when you met with Bethany?") in the number of correct statements children made, $F(2,60)=4.25, p=.019$. Children in the worksheet group produced more correct statements in their open-ended responses than did children in the control group. The documentation children produced slightly more responses than did the control group. (Post-hoc tests indicated that the mean difference between the worksheet and control condition was significant $(\mathrm{p}=.03)$, the difference between the documentation and control condition was not significant $(\mathrm{p}=1.0)$, and the difference between the documentation and worksheet condition was marginally significant $(p=.065)$.) No other significant differences existed for event questions analyzed on the individual level (see Table 6).

All memory outcome variables were then summed across the event questions and the totals were analyzed using the two-way ANOVA models described above. The total correct number of props children said they held during event questions significantly differed by gender $\mathrm{F}(1,60)=4.32, \mathrm{p}=.042$. Male children $(\mathrm{M}=1.12, \mathrm{SD}=.609)$ remembered more props they held than female children $(\mathrm{M}=.839, \mathrm{SD}=.454)$. There were no condition, classroom or interaction effects for this variable. 
Table 6.

Average Scores on Event Questions by Condition

Condition

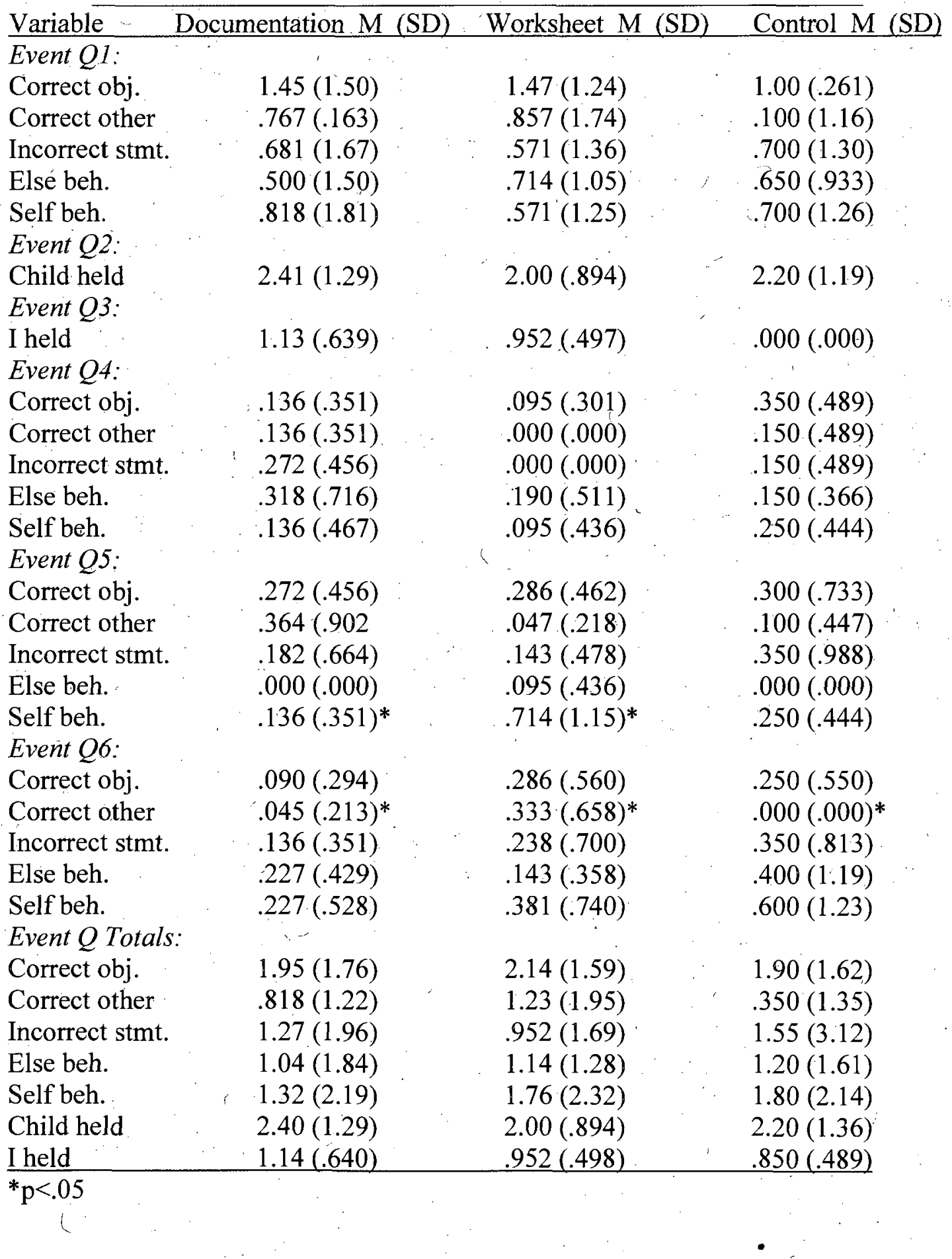




\section{Factual Questions:}

There was one question during the memory interview that was explicitly labeled "Factual." It was an open-ended question that asked, "Now I'm interested in finding out everything that you know about the country of Panama. What are some of the things that you can tell me about the country of Panama? Can you tell me anything else?" Two-way ANOVAs revealed a significant difference between classrooms in the number of other correct statements children made $\mathrm{F}(1,60)=5.30, \mathrm{p}=.025$. Kindergarten children $(\mathrm{M}=.697$, $\mathrm{SD}=1.21$ ) made a greater number of other correct statements than preschool children $(\mathrm{M}=.167, \mathrm{SD}=.461)$. There were no other condition, classroom, gender or interaction effects.

Item (word) recognition questions:

There were eight item (word) recognition questions in the memory interview. These questions had children respond yes or no if they had learned about certain objects. Correct responses were summed so that a total correct word recognition value was obtained. Overall, performance was high for these questions (Documentation $\mathrm{M}=7.00$, $\mathrm{SD}=1.45$, Worksheet $\mathrm{M}=7.33, \mathrm{SD}=.730$, Control $\mathrm{M}=6.45, \mathrm{SD}=1.31$, Total $\mathrm{M}=6.93$, $\mathrm{SD}=1.24)$. Two-way ANOVA tests indicated a significant classroom effect on correct word recognition $\mathrm{F}(1,60)=5.75, \mathrm{p}=.02$, in which preschool children $(\mathrm{M}=6.56, \mathrm{SD}=1.50)$ remembered less than kindergarten children $(\mathrm{M}=7.27, \mathrm{SD}=.839)$. A condition effect approached significance $F(2,60)=2.96, p=.060$. Post hoc tests revealed that the difference between the control and worksheet groups approached significance $(p=.059)$. There were no gender or interaction effects. 


\section{Picture recognition questions:}

There were five picture recognition questions in the memory interview. These questions asked children to identify which images they had seen in session one or two and which they had not seen. Correct responses were summed so that a total correct picture recognition score was obtained. Overall, performance was high for these questions (Documentation $\mathrm{M}=4.09, \mathrm{SD}=.971$, Worksheet $\mathrm{M}=3.81, \mathrm{SD}=.873$, Control $\mathrm{M}=3.50, \mathrm{SD}=1.05$, Total $\mathrm{M}=3.81, \mathrm{SD}=.981$ ). Two-way ANOVA tests indicated a classroom effect $\mathrm{F}(1,60)=4.27, \mathrm{p}=.045$, in which preschool children $(\mathrm{M}=3.53, \mathrm{SD}=1.01)$. remembered less than kindergarten children $(\mathrm{M}=4.06, \mathrm{SD}=899)$. There were no condition, gender or interaction effects.

\section{Source monitoring questions:}

There were four source monitoring questions in the memory interview. Correct responses were summed so that a total correct source monitoring score was obtained.

Overall, performance was good for these questions (Documentation $\mathrm{M}=3.09, \mathrm{SD}=.971$, Worksheet $\mathrm{M}=3.09, \mathrm{SD}=1.04$, Control $\mathrm{M}=2.70, \mathrm{SD}=.978$, Total $\mathrm{M}=2.96, \mathrm{SD}=.999$ ). Two-way ANOVA tests indicated a classroom effect $\mathrm{F}(1,60)=4.21, \widehat{\mathrm{p}}=.045$, in which preschool children $(\mathrm{M}=2.70, \mathrm{SD}=1.02)$ remembered less than kindergarten children $(\mathrm{M}=3.21, \mathrm{SD}=.927)$. There were no condition, gender or interaction effects.

\section{Specific Fact Questions:}

There were seven specific fact questions asked in the memory interview. Each question had three parts: a broad open-ended question, a prompted open-ended question, and a forced-choice question. (All means and standard deviations for specific fact 
questions are presented in Table 7 by condition and in Table 8 by classroom). The broad open-ended questions were coded and transcribed. Two-way ANOVA tests revealed no significant differences on any of the memory outcome variables by condition, classroom, or gender and no interaction effects. Total values for the prompted open-ended questions and forced choice questions were then calculated for each memory outcome variable. The total values were also tested using a series of two-way ANOVAs. Analyses revealed a significant difference between condition in the number of total specific facts children remembered, $F(2,60)=9.34, p<.001$. Children in the worksheet and documentation conditions remembered more total specific facts than did children in the control condition. Post-hoc tests revealed significant differences between the documentation and control conditions $(\mathrm{p}<.001)$ and the worksheet and control conditions $(\mathrm{p}<.001)$. A classroom effect was also found for this variable $F(1,60)=5.54, p=.022$, in which preschool children remembered fewer facts than did kindergarten children. There were no effects of gender and no significant interaction effects for this variable.

Specific facts remembered were then analyzed within the open-ended questions and the forced choice questions separately. It was found that the open-ended (recall) questions significantly differed by condition, $\mathrm{F}(2,60)=5.85, \mathrm{p}=.005$. Post-hoc tests revealed significant differences between the documentation and control conditions $(p=.005)$ and the worksheet and control conditions ( $p=.027)$. The forced choice (recognition) questions did not differ by condition $\mathrm{F}(2,60)=2.27, \mathrm{p}=.112$. No classroom, gender or interaction effects were found.

Props Children Held in Specific Fact Questions: 
In session one, children each held one of three available props. The specific fact questions were analyzed to investigate the rate of correct information children remembered related to the prop they held. Of the total specific fact questions asked about session one, six were about a prop they held and 12 were about props they did not hold. Total scores for correct information on these questions were calculated and run in a series of two-way ANOVAs. Results revealed a difference between conditions in the total number of specific facts children remembered for the prop they held, $F(2,60)=7.95$, $\mathrm{p}=.001$. Children in the worksheet and documentation conditions remembered more facts than did children in the control condition. Post-hoc tests revealed a significant difference between the worksheet and control groups $(\mathrm{p}<.001)$. A classroom effect also existed in which preschool children remembered fewer facts for the prop they held than did kindergarten children $F(1,60)=7.74, p=.007$. No effects of gender and no interaction effects were found. In regards to the total number of specific facts children remember for the props that they did not hold in session one a significant difference emerged between conditions $\mathrm{F}(1,60)=3.34, \mathrm{p}=.010)$. Post-hoc test indicate the difference exists between documentation and control conditions $(\mathrm{p}=.004)$ and between worksheet and control conditions $(\mathrm{p}<.001)$.

Specific facts remembered based on the props children held were then analyzed within the open-ended questions and the forced choice questions separately. Neither open-ended (recall) nor forced choice (recognition) questions significantly differed by condition. A gender effect was revealed for open-ended questions in which males $(\mathrm{M}=.969, \mathrm{SD}=.822)$ remembered more facts for the prop they held than did females 
$(\mathrm{M}=.581, \mathrm{SD}=.765) \mathrm{F}(1,60)=4.58, \mathrm{p}=.037$. No other classroom, gender, or interaction effects were.found.

Finally, a t-test was computed to determine if children remembered specific fact information related to the prop they held and a higher rate than specific fact information related to the props they did not hold. It was found that children's memory did not differ based on prop held $\mathrm{t}(62)=-.528, \mathrm{p}=.599$.

Session One \& Two Specific Facts:

In session one children learned three main facts and 9 sub-facts. In session two children learned two more main facts. The specific fact questions were analyzed to investigate the rate of correct information children remembered within session one and session two separately. Total scores for correct information for session one and two were calculated using the specific fact questions. These total scores were then run in a series of two-way ANOVAs. For total specific facts learned in session one, results revealed a significant difference by condition, $\mathrm{F}(2,60)=14.84, \mathrm{p}<.001$. Children in the worksheet and documentation conditions remembered more facts than children in the control condition. Post-hoc testes revealed significant differences between the worksheet and control condition $(\mathrm{p}<.001)$ and between the documentation and control condition $(\mathrm{p}=.002)$. A classroom effect was also revealed, $F(1,60)=4.20, p=.035$. Preschool children remembered fewer total specific facts in session one than did kindergarten children. No gender or interaction effects were found. 
Specific facts learned in session one were then further anályzed within the openended questions and the forced choice questions separately. For specific facts remembered in open ended-questions a condition effect was revealed, $F(2,60)=5.87$, $\mathrm{p}=.005$. Children in the worksheet and documentation conditions remembered more facts than did children in the control condition. Post-hoc tests indicated significant differences between the documentation and control conditions $(\mathrm{p}=.006)$ and the worksheet and control conditions $(p=.023)$. A classroom effect was also revealed, $F(1,60)=4.20, p=.045$, in which preschool children remembered fewer facts than did kindergarten children. In the forced choice questions a condition effect was again revealed, $F(2,60)=4.97, p=.010$. Children in the worksheet and documentation group remembered more facts during forced choice questions than did children in the control children. Post-hoc tests indicated a significant difference between worksheet and control conditions $(p=.012)$, and a marginal difference between documentation and control conditions ( $\mathrm{p}=.058)$. There were no gender or interaction effects found. For facts learned in session two, no significant differences were found in children's memory by condition, classroom, or gender.

Reminded \& Not Reminded Specific Facts:

In session two children in the worksheet and documentation conditions were reminded of certain sub-facts and not others. À series of two-way ANOVA tests were conducted to determine if memory differed between facts that children were reminded of compared to those they were not reminded of. For specific facts not reminded of during session two no significant difference was found in children's memory by condition. For specific facts that were reminded of, children's memory for total facts differed by 
condition $\mathrm{F}(2,60)=14.23, \mathrm{p}<.001$. Children in the worksheet and documentation conditions remembered more facts than did children in the control condition. Post-hoc tests revealed significant differences between the worksheet and control $(\mathrm{p}<.001)$ conditions as well as between the documentation and control conditions $(\mathrm{p}=.003)$. A classroom effect revealed that preschool children remembered fewer total facts reminded of than did kindergarten children $\mathrm{F}(1,60)=9.33, \mathrm{p}=.003$.

Specific facts reminded of in session two were further analyzed within the openended questions and the forced choice questions separately. For specific facts remembered in open-ended questions a condition effect was revealed, $\mathrm{F}(2,60)=7.713$, $\mathrm{p}<.001$. Children in the worksheet and documentation conditions remembered more facts than did children in the control condition. Post-hoc tests revealed significant differences between the worksheet and control $(\mathrm{p}=.002)$ conditions as well as between the documentation and control conditions $(\mathrm{p}=.004)$. A classroom effect revealed that preschool children remembered fewer total facts reminded of than did kindergarten children $F(1,60)=3.99, p=.050$. For specific facts remembered in forced choice questions a condition effect was revealed, $F(2,60)=3.89, p=.026$. Children in the worksheet and documentation conditions remembered more facts than did children in the control condition. Post-hoc tests revealed a significant difference between the worksheet and control conditions $(\mathrm{p}=.032)$. There were no gender or interaction effects found. For facts not reminded of during session two, no significant differences were found in children's memory by condition, classroom, or gender. 
Table 7.

Average Scores on the Specific Fact Questions by Condition

Condition

\begin{tabular}{|c|c|c|c|c|}
\hline \multirow{2}{*}{\multicolumn{5}{|c|}{ Documentation, M (SD) }} \\
\hline & & & & \\
\hline \multicolumn{5}{|c|}{ Broad Open-ended $Q$} \\
\hline Correct other B & $3.09(3.01)$ & & $4.04(2.54)$ & $2.95(2.56)$ \\
\hline Incorrect stmt. B & $2.72(2.71)$ & & $4.19(3.63)$ & $5.30(6.14)$ \\
\hline Else beh B & $.318(.646)$ & & $.238(.625)$ & $.150(.489)$ \\
\hline Self beh B: & $.273(.702)$ & & $.095(.436)$ & $.250(.716)$ \\
\hline \multicolumn{5}{|c|}{ Prompted Open \& Forced Choice $Q$ : } \\
\hline SF Open C & $3.31(1.64)^{*}$ & & $3.04(1.69)^{*}$ & $1.70(1.49)^{*}$ \\
\hline SF Choice C & $7.86(1.49)$ & & $8.62(1.46)$ & $7.60(1.85)$ \\
\hline SF Total C & $14.50(3.13)^{*}$ & & $14.71(3.06)$ & $11.00(3.15)^{*}$ \\
\hline \multicolumn{5}{|l|}{ Props Child Held: } \\
\hline Prop Open C & $818(.795)$ & & $1.00(.837)$ & $.500(.761)$ \\
\hline Prop Choice C & $1.64(.848)$ & & $1,92(.865)$ & $1.55(.759)$ \\
\hline Prop Total C & $2.45(.912)$ & & $2.95(.864)^{*}$ & $1.90(.968)^{*}$ \\
\hline Prop Total Not Held & $5.27(1.07)^{*}$ & & $5.57(1.16)^{* *}$ & $4.20(1.19)^{*}$ \\
\hline \multicolumn{5}{|l|}{ Session One: } \\
\hline SF Open C & $2.95(1.43)^{*}$ & & $2.76(1.37)^{*}$ & $1.60(1.31)^{*}$ \\
\hline SF Choice C & $4.77(1.31)$ & & $5.76(1.26)^{*}$ & $4.50(1.47)^{*}$ \\
\hline SF Total C & $7.73(1.42)^{*}$ & & $8.52(1.40)^{* *}$ & $6.10(1.58)^{* *}$ \\
\hline \multicolumn{5}{|l|}{ Session Two: } \\
\hline SF Open C & $.364(.581)$ & & $.286(.646)$ & $.100(.308)$ \\
\hline SF Choice C & $3.09(.684)$ & & $2.86(.792)$ & $3.10(.718)$ \\
\hline SF Total C & $3.45(.671)$ & & $3.14(.655)$ & $3.20(.768)$ \\
\hline \multicolumn{5}{|l|}{ Facts Reminded: } \\
\hline SF Open C & $1.86(1.08)^{*}$ & & $1.95(1.20)^{*}$ & $.800(.833)^{*}$ \\
\hline SF Choice C & $3.45(.962)$ & & $4.05(.805)^{*}$ & $3.25(1.16)^{*}$ \\
\hline SF Total C & $5.32(1.21)^{*}$ & & $6.00(1.18)^{* *}$ & $4.05(1.36)^{* *}$ \\
\hline \multicolumn{5}{|c|}{ Facts Not Reminded: } \\
\hline SF Open C & $1.22(.833)$ & , & $.809(.601)$ & $.800(.615)$ \\
\hline SF Choice $\mathrm{C}$ & $1.50(.740)$ & & $1.90(.625)$ & $1.60(.680)$ \\
\hline SF Total C & $2.59(.590)$ & & $2.71(.463)$ & $2.40(.598)$ \\
\hline
\end{tabular}


Table 8 .

Average Scores on the Specific Fact Questions by Classroom

Classroom

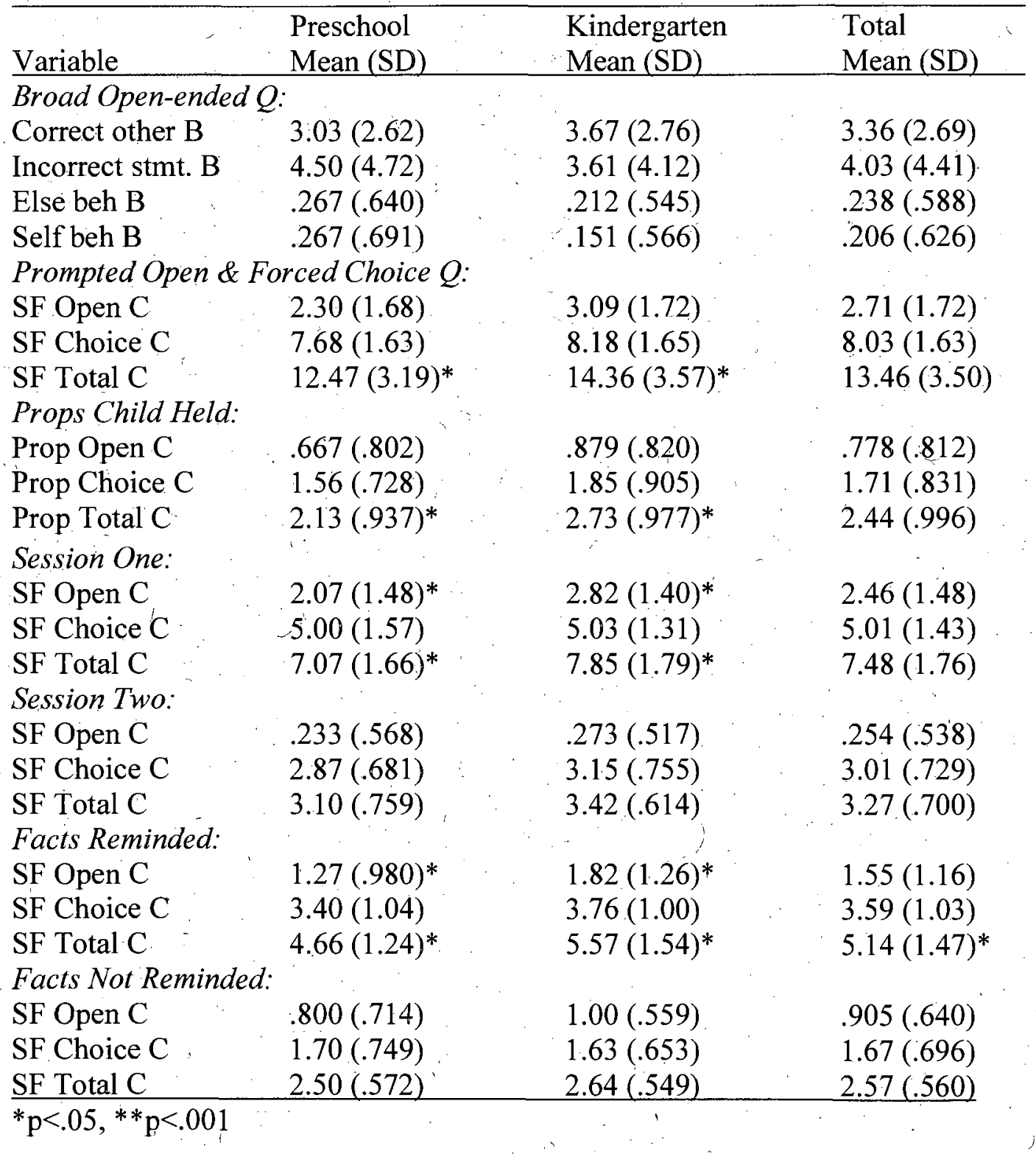




\section{Word Count:}

For the questions that were transcribed, the number of words children spoke was totaled. One-way ANOVA tests were run to compare the number of words spoken between conditions for the entire transcript, during specific fact questions, and during event questions. No significant differences were found between conditions (see Table 9). A series of t-tests using the Bonferroni correction revealed that the transcription word count total did not differ by gender or classroom (see Table 10 and Table 11). 
Table 9.

Average Word Count by Condition

Condition

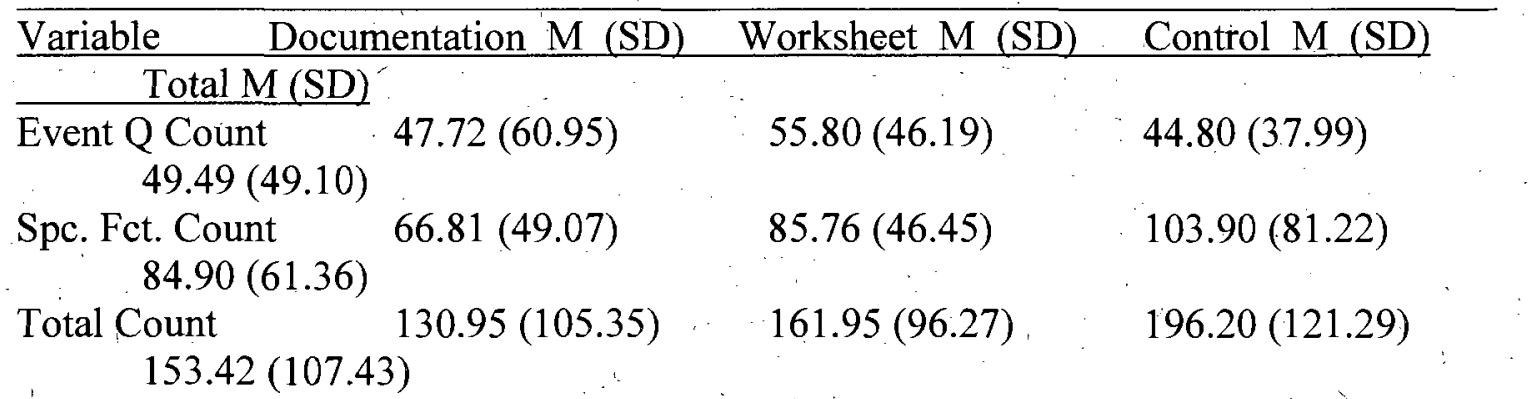


Table 10.

Average Word Count by Gender

Gender

\begin{tabular}{lll}
\hline Variable & Male M (SD) & Female M (SD) \\
\hline Event Q count & $46.75(34.59)$ & $52.32(61.09)$ \\
Spc. Fct. Count & $88.78(55.51)$ & $80.90(67.57)$ \\
Total Count & $157.16(96.28)$ & $149.58(119.36)$
\end{tabular}


Table 11.

Average Word Count by Classroom

Classroom

Variable

Preschool M (SD) Kindergarten M (SD)

Event Q count

$50.50(58.41)$

$48.57(39.71)$

Spc. Fct. Count

$89.73(66.01)$

$80.51(57.49)$

Total Count

$158.63(117.63) \quad 148.69(98.63)$ 


\section{CHAPTER VIII}

\section{DISCUSSION}

Based on the findings of this study, it can be concluded that documentation serves as an effective teaching method for young children's learning and memory. During the memory interview, children in the documentation condition remembered equally as much information as the children in the worksheet condition and more than children in the control condition. These findings are consistent with Reggio educators' claims that documentation provides learning and memory enhancing effects (Goldhaber \& Smith, 1997; Katz \& Chard, 1997: Project Zero, 2001, 2003; Rinaldi, 2006, 1998; Thornton \& Brunton, 2005; Wurm, 2005).

In the current study documentation was carefully isolated from naturally occurring teaching methods. Children were pulled from their'classrooms to meet with the researcher in a separate room of their school. The experimental sessions were all scripted, were matched in regards to time spent with children between conditions, and were videorecorded. This procedure allowed us to control for extraneous variables which was advantageous because it provided clear results regarding the impact of documentation on young children's memory. The findings indicate that documentation (in this isolated form) works as a successful reminder. When used as part of an organic educational experience the effects should be exaggerated especially when utilized congruently with 
the other important teaching methods and values of the Reggio approach. For example, Reggio uses an emergent curriculum whereby the topics that are studied come from children's interests and the facts they learn are discovered through exploration (Malaguzzi, 1998). Based on this, children have an intrinsic interest in the topics they study, unlike the current study where the topic was chosen and facts were presented. Pairing documentation with an emergent curriculum should only increase its effectiveness.

Although the evidence from this study suggests that documentation served as an effective reminder, overall it was not found that documentation children outperformed children in the worksheet condition. These results were inconsistent with our predictions; however there are several possible explanations. Specifically, the effectiveness of these particular worksheets should be considered. First, the worksheets provided children with many of the same memory enhancing elements as the documentation posters. Both reminders presented children with the very same pictures of the main facts (e.g. the flag, harpy eagle, and mejoranera guitar). Each reminder also presented children with text restating the sub-facts children learned in session one. Second, the primary researcher created the worksheets to be enjoyable and to specifically remind children of the material they had learned.

Third, the worksheets had children actively engaged in conversation in the same way as the documentation children. The researchers' portions of the conversations were scripted to mirror each other as much as possible. In American school systems traditional use of worksheets is starkly different than in the current study. The worksheets are often 
dull, black and white, and tedious for children to complete. Worksheets are usually done quietly and individually in children's own personal workspace where they are rarely able to converse one-on-one with their teachers (Kamii, 1985, Jenson, 2009). In the current study children completed worksheets alongside the researcher who actively engaged the children in conversation throughout the entire session. Based on the presence of such conversations, the reminding effect of the worksheet condition supports conclusions that conversations enhance children's memory as reported by developmental psychologists (McGuigan \& Salmon, 2004; Pillemer, 1998; Reese et al., 1993). Based on the characteristics of these particular worksheets it is not surprising that they reminded children as efficiently as documentation.

\section{Episodic Memory}

The results indicated significant differences for two event questions from the memory interview. First, children in the worksheet condition remembered a greater number of their own behaviors when asked what they said during the learning event than did the children in the documentation condition. These results should be interpreted with caution. This question asked children what they said during the learning event, not what they did. The coding procedure extracted children's mentions of their own behaviors. Anecdotally, it appeared that children in the documentation condition were making more statements about what they actually said while children in the worksheet condition were providing answers about behaviors. This pattern of responses is expected because children in the documentation condition revisited their own statements in session two 
which might have aided them in answering what they said without referring to what they were doing.

The second significant difference found for event questions revealed that children in the documentation and worksheet conditions remembered a greater number of correct statements (measured by the amount of accurate mentions of related props or ideas discussed during the learning event) than did control children when asked to provide any additional information about what happened during the learning events. This result indicates that documentation was able to remind children of event-related information (episodic memory). This conclusion is consistent with our expectations and previous research that has confirmed young children's ability to remember event information. For example, results from studies using the deferred imitation paradigm indicate that children as young as nine-months-old can imitate single actions from an event witnessed the previous day (Meltzoff \& Moore, 1988), while children 24 to 30 months can reproduce three-step actions two to three weeks later (Deocampo \& Hudson, 2003). In Deocampo and Hudson's (2003) and Sheffield and Hudson's (2006) studies, children's memory was further enhanced when they were reminded of the original event using photographs prior to the memory interview. Furthermore, research investigating the role of conversations between children and adults suggests that the original event and the conversation about the event both serve as encoding opportunities. This extra time to organize event representations in memory explains why conversations are effective for their reinstatement and preservation (McGuigan \& Salmon, 2004). 
Based on the literature it was expected that during the present study documentation children would outperform the worksheet and the control children during event questions. This was expected because documentation exposed them to actual photographs taken during the learning event as well as the occasion to converse with the researcher as they reviewed the poster together. Although some important differences were observed between conditions, overall the children's answers to event questions were limited and the documentation group did not exceed past the worksheet or control groups. in many ways. For example, all children mentioned other people's behaviors during the learning event an average of 1.13 times during all of the event questions. This mean is low, as children could have remembered any number of behaviors that occurred during the learning event (sitting, playing, talking, waving the flag, etc).

It could be that the event questions themselves were not fine enough tools for extracting the type of information that was being requested. Children were providing just as much factual information in their answers as they were event related information, suggesting that they were not completely understanding what was being asked of them. It appears to be difficult for young children to differentiate between "what did you do" and "what do you know" type of questions. The trouble children had with these questions is similar to that which is seen when they are presented with source monitoring questions asking "when/how do you know". These questions require children to remember events in which learning took place. Three to five-year-old children often claim to "just know" information (Gopnik \& Graf, 1988). Wheeler (2000) posits that "the difference must involve some conceptual limitation on the part of three and four-year-old children; although they can learn complex actions from single events they cannot reflect on their 
experience of the events by mentally traveling back in time to relive them (p.604)." Interestingly the source monitoring questions asked in the present study did not differ by condition or classroom mainly because performance came close to ceiling, with children answering on average 2.97 of the four questions correctly.

Future research would benefit from revising the event questions used in the current study so that they are clearer to young children. I also propose staging an interesting/unique event to occur while children are learning, such as a funny interrupting alarm or person entering the learning event, or "accidentally" dropping all the materials causing a ścene. If this unique event information is recalled at a differing rate between conditions we would have clearer evidence for a facilitative effect in episodic memory. Work should also be done further investigating the role that conversations play in reviewing documentation, particularly those that occur between teachers and children, and parents and children. A research study could be conducted which stages a scripted learning event in a large group setting within a classroom. After a time delay adult and child dyads could come into the lab to talk together about documentation made available for them. Analysis of the participants' conversations could reveal the information that adults are highlighting and how they are helping to structure children's own recollections of the learning events. Children's contributions could also reveal interesting insights into their event memory processes.

\section{Semantic Memory}

The results indicated differences between conditions for the specific fact questions. It was found that children in the documentation and worksheet conditions 
remembered a greater number of total specific facts than did children in the control condition. This effect occurred within the open-ended (recall) questions but not within the forced-choice (recognition) questions. For the total number of specific facts learned in session one the same results emerged but for facts learned in session two (after the reminder tasks had occurred) there were no differences among conditions. Finally, for the number of specific facts that children were reminded of in session two, children's memory for total facts differed by condition. In comparison with children in the control condition, children in the worksheet and documentation conditions again remembered a greater number of total specific facts, a greater number of facts in open-ended questions, and a greater number of facts in the forced choice questions. Specific facts not reminded of did not differ by condition.

In sum, documentation reminds children of specific factual or content information (semantic memory) and this was especially true for facts learned in session one and facts that were explicitly reminded of during session two. Furthermore it is during the openended questions that the largest effects are found indicating that children are recalling information, not just recognizing it. These findings support Reggio educators' claims regarding the effects of documentation on young children's learning and memory. They suggest that it is the opportunity documentation provides to revisit information that promotes learning (Katz \& Chard, 1997; Fawcett \& Hay, 2004; Hewett, 2001). The current findings affirm that as the children reviewed the documentation their memory processes were being supported. 
Rinaldi (2006) suggests that the communication and reflection surrounding documentation is of particular importance for memory. The conversation literature supports this claim. It has consistently been found that the events that are discussed with adults are more likely to be recalled at a later time period than those that are not (Fivush, 1991; Fivush et al., 1991; Handen et al., 2001; McGuigan \& Salmon, 2004; Pillemer, 1998; Tessler \& Nelson, 1994). In the present study the children and researcher were engaged in a cònversation about the past learning event and information while they reviewed the documentation together. Furthermore, children were exposed to quotations that they themselves had spoken. Previous research has found that the words a child speaks of their own accord are the aspects that are most readily remembered (McGuigan \& Salmon, 2004).

Of further interest is the finding that children in the documentation and worksheet conditions outperform control children in their recollection more so than in their recognition of specific facts. This is especially true when taking into consideration the results from the item/word and picture recognition questions which did not differ at all by condition. This finding suggests that documentation has a strong reminding effect because recalling information is a tougher task than recognizing it. When recalling information people use a "generate and recognize" process. In this process people first work to retrieve the information by searching their memory and then they must recognize that they have found the correct information. This is more effortful than simply recognizing through exposure to external stimuli (Andrade \& May, 2004). In fact, children performed at ceiling on recognition questions getting on average 3.81 picture questions correct out of four and 6.94 item questions correct out of seven. 
Additional differences between conditions were found in the number of specific facts remembered based on the props children held. Children in the worksheet and documentation conditions remembered a greater number of specific facts for the props they held than did children in the control condition. This finding is supported in previous educational literature which suggests that it is best practice to get students actively involved in the learning process by manipulating objects, physically moving around, and intensifying their emotional experience while they learn (Jensòn, 2009). Hands on learning is described as more dynamic, interesting, and exciting for children and this alone can increase retention of related content information and episodic memory (Feinstein, 2006; Sprenger, 1999).

Though no specific predictions were made regarding gender, previous research has identified gender differences in children's memory (Buckner \& Fivush, 1988; Kail \& Seigel, 1977; Herlitz \& Yonker, 2002). In the current study, analyses exploring gender found that males remembered more facts for the props they held than did female children during the open-ended specific fact questions. This was also true for event questions in which male children remembered a greater number of props that they held than female children. Overall, remembering the props that were held and recalling specific facts related to those props was easier for male children than female children. Based on observation, female children appeared to focus more on the social context of the event whereas male children focused more on the props and physically manipulating them. It is also possible that the props themselves were more appealing to males or were stereotyped as male toys (i.e. the boat, guitar, eagle, and map). 
In sum, the present study found benefits in children's semantic memory with exposure to documentation. Future work would benefit from examining other forms of documentation. Documentation is not only seen in the poster format that was used here, but is also found as books, notebooks, diaries, exhibits of artifacts, audiocassettes; messages, and letters (Gandini, 2004; Project Zero, 2001). Investigating alternative formats could lend support to the current findings and expand understanding about the processes by which young children remember educational material.

Documentation should also be studied in a more naturalistic setting. A naturalistic study would involve observation of schools that employ the Reggio approach. Records would be kept of how teachers naturally employ documentation and how children interact with it as they normally would. A memory interview could then be conducted in a similar way to the current study, asking children what they remember from the learning event and the content that they learned. Observations and interviews of children in more traditional teaching/learning environments could be used as a comparison. Just as useful are more controlled experiments. For example, it would be interesting and beneficial to teach children in a whole class setting (such as during circle time). Documentation could then be hung in the classroom as it naturally is in Reggio classrooms, and memory. interviews conducted three weeks later.

\section{Classroom (age) differences}

The amount of information children recalled during the memory interview suggests a developmental trend between classrooms whereby preschool children remember less information than kindergarten children. This was evident for answers to 
the open-ended factual question that asked children to remember everything they knew about Panama. Here, the number of other correct statements (i.e. sub-fact information) that children reported differed. Children's responses to the item (word) recognition questions, picture recognition, source monitoring, and total specific fact questions all revealed the same developmental trend. Furthermore, preschool children remembered fewer total specific facts, facts for the props they held, session one total facts and facts from open-ended questions than did kindergarten children.

Past research has found a similar developmental trend in young children's memory (Bauer, 2007; Hammond \& Fivush, 1991). In a study of childhood amnesia, Pillemer, Picariello, and Pruett (1994) interviewed younger (3.5 years-old) and older (4.5 years-old) preschool children about an emergency evacuation at their school that occurred two weeks previously. Results indicated that the older preschool children gave more intact narratives with correct information involving the temporal and causal sequence of events. Conversely, the younger preschool children's narratives were fragmented. Seven years later the children were again interviewed. It was found that only the older children had convincing evidence of long-term memory for the evacuation event.

Developmental literature suggests reasons why older children remember more than younger children. The primary explanation is the dramatic changes that occur in basic cognitive processes. Skills such as encoding, storage, retrieval, and reporting information all improve with age (Ornstein \& Haden, 2001; Ornstein, Baker-Ward, Gordon, \& Merritt, 1997). Furthermore, children's metacognitive knowledge increases. 
This particular knowledge concerns children's awareness of their own personal cognitive processes and it parallels their memory development. As children age they begin to understand how to focus their attention, intentions, and thinking (Flavell, 1999, 2000; Parault \& Schwanenflugel, 2000). Another explanation for age related differences in memory processes is the amount of general knowledge children have. As children age their general knowledge increases and this improves the flow of information in the memory system. It is easier to encode, organize, and retrieve new-information when individuals have prior knowledge to build upon (Ornstien \& Haden, 2001; Schneider \& Bjorklund, 1998). Finally, children's use of memory strategies or mnemonic aids increases with age. Memory strategies include rehearsal, organization, and elaboration. Young preschool children touch objects they are asked to remember while elementary school children often repeat the information verbally (DeLoache, 1984).

The current study used participants within a limited age range (between 4.5 and 6years-old). It would be interesting to replicate this work with a larger age range to see if documentation has beneficial effects at different ages. This would also contribute to understanding the developmental trend observed between preschool and kindergarten children's memory performance. The current study was also limited in the amount of diversity in the schools and in the sample of children who participated. Participants came from predominantly white, middle to upper class homes in suburban New England. It could be that children from more diverse backgrounds or from significantly different schools (measured by quality using the ECERS-R), perform differently than was found in this study. 


\section{Conclusion}

The present study indicated that documentation, which is integral to the Reggio Emilia teaching method, worked as an effective reminder for young children's episodic and semantic memory. Children in the documentation and worksheet conditions outperformed children in the control condition in an event question and in multiple specific fact questions. This effect was particularly apparent in open-ended (recollection) questions indicating that children were not just recognizing information but actively recalling it. Children's memory for information related to the props they held was also remembered at a greater rate in the documentation and worksheet groups than in the control group. Furthermore, there were differences between younger and older children whereby kindergarten children remembered a greater amount during the mémory interview than did preschool children. Overall, the findings of this study point to the effectiveness of documentation in enhancing young children's learning and memory. Though the Reggio Emilia approach to early childhood education is considered nontraditional in American society, the empirical evidence from this study suggests that documentation is valid and useful, even for children who have not been exposed to it before. 


\section{LIST OF REFERENCES}

Andrade, J., \& May, J. (2004). Cognitive Psychology. Garland Science/BIOS Scientific Publishers, Oxon UK.

Barerra, M.A., \& Mayrer, D. (1981). Recognition of mother's photographed face by three-month-old. Child Development, 52, 714-716.

Bauer, P.J. (2007). Remembering the times of our lives: Memory in infancy and beyond. Mahwah, NJ: Erlbaum.

Boland, A.M., Haden, C.A., \& Ornstein, P.A. (2003). Boosting children's memory by training mothers in the use of an elaborative conversational style as events unfold. Journal of Cognition and Development; 4, 39-64.

Buckner, J.P., \& Fivush, R. (1998). Gender and self in children's autobiographical narratives. Applied Cognitive Psychology, 12, 407-429.

Carney, R.N., \& Levin, J.R. (2002). Pịctorial illustrations still improve students' learning from text. Educational Psychology Review, 14(1), 5-26.

Child Study and Development Center; About CSDC. (2008). Retrieved February 3, 2009, from Child Study and Development Center Web Site: http://csdc.unh.edu/About/

Cleveland, E.S., \& Reese, E. (2005). Maternal structure and autonomy support in conversations about the past: Contributions to children's autobiographical memory. Developmental Psychology, 41, 376-388.

Deocampo, J., \& Hudson, J.A. (2003). Reinstatement of 2-year-olds' event memory using photographs. Memory, 11(1), 13-25.

DeLoache, J.S. (1991). Symbolic functioning in very young children: understanding of pictures and models. Child Development, 62, 736-752.

DeLoache, J.S., \& Burns, N.M. (1993). Symbolic development in young children; understanding models and pictures. In C. Pratt and A.F. Garton (eds) Systems of Representation Children: Development and Use (pp. 91-112). Chichester, England: Wiley. 
DeLoache, J.S., \& Burns, N.M. (1994). Early understanding of the representational function of pictures. Cognition, 52, 83-110.

DeLoache, J.S., Pierroutsakos, S.L., \& Troseth, G.L. (1996). The three R's of pectoral competence. Annals of Child Development, 12,1-48.

DeLoache, J.S., Strauss, M., \& Maynard, J. (1979). Picture perception in infancy. Infant Behavior and Development, 2, 77-89.

Edwards, C., Gandini, L., \& Forman, G. (1998). The hundred languages of children: the Reggio Emilia approach-advanced reflections $2^{\text {nd }}$ edition. Greenwich, CT: Alex Publishing.

Edwards, D., and Midleton, D. (1988). Conversational remembering and family relationships: how children learn to remember. Journal of Social and Personal Relationships, 5, 3-25

DeLoach, J.S. (1984). Oh where, of where: Memory-based searching by very young children. In C. Sophian (Ed.), Origins of cognitive skills. Hillsdale, NJ: Erlbaum.

Digdon, N., Pressley, M., \& Levin, J. (1985). Preschoolers' learning when pictures do not tell the whole story. Educational Communication \& Technology Journal, 33 (2), $139-145$.

Dosher, B.A., \& Russo, J.E. (1976). Memory for internally generated stimuli. Journal of Experimental Psychology: Human Learning and Memory, 2, 633-640.

Fang, Z. (1996). Illustration, text, and the child reader. What are picture in children's storybooks for? Read. Horizons, 37, 130-142.

Fawcett, M., \& Hay, P. (2004). 5x5x5 = Creativity in the early years. Jade NSEAD, 23, 234-245.

Feinstein, S. (2006). The Praeger Handbook of Learning and the Brain. Greenwood Publishing, Westport, CT.

Fivush, R. (1991). The social construction of personal narratives. Merrill-Palmer Quarterly, 37, 59-81

Fivush, R., Hamond, N.R., Harsch, N., Singer, N., \& Wolf, A. (1991). Content and consistency in young children's autobiographical recall. Discourse Processes, 14 , $373-388$. 
Fivush, R., Pipe, M.E., Murachver, T., \& Reese, E. (1997). Events spoken and unspoken: Implications of language and memory development for the recovered memory debate. In M.A. Conway (Ed.), Recovered memories and false memories. Debates in psychology (pp. 34-62). Oxford, England: Oxford University Press.

Fivush, R., Reese, E., \& Haden, C. (2006). Elaborating on elaborations: Role of maternal reminiscing style in cognitive and socioemotional development. Child Development, 77, 1568-1588.

Flavell, J.H. (1999). Cognitive development: Children's knowledge about the mind. Annual Review of Psychology, 50, 21-45.

Flavell, J.H. (2000). Development of children's knowledge about the mental world. International Journal of Behavioral Development, 24, 15-23.

Forman, G. (1999). Beyond the attentive eye: The importance of theory for the practice of documentation. Canadian Children, 24, 4-8.

Gandini, L. (2004). Foundations of the Reggio Emilia approach. In J. Hendrick (Ed.), Next steps toward teaching the Reggio way. Accepting the challenge to change $2^{\text {nd }}$. edition. Upper Saddle River, New Jersey: Prentice Hall.

Garrison City Early Childhood Center; Programs. (2006). Retrieved February 3, 2009े, from Garrison City Early Childhood Center Web Site: http://www.gcecc.net/programs.htm

Goldhaber, J., \& Smith, D. (1997). "You look at things differently:" The role of documentation in the professional development of a campus child care center staff. Early Childhood Education Journal, 25, 3-10.

Gopnik, A., \& Graf., P. (1988). Knowing how you know: Young children's ability to identify and remember the sources of their beliefs. Child Development, 59 (5). 1366-1371.

Growing Places; Pinkham Road Preschool (2006). Retrieved February 3, 2009 from Growing Places Web Site: http://www.growingplacesnh.org/Packer_Falls.html

Greenhoot, A.F., \& Semb, P.A. (2008). Do illustrations enhance preschoolers' memories for stories? Age-related change in the picture facilitation effect. Journal of Experimental Child Psychology, 99, 271-287.

Haden, C.A., Ornstein, P.A., Eckerman, C.O., \& Didow, S.M. (2001). Mother-child conversational interactions as events unfold: Linkages to subsequent remembering. Child Development, 72, 1016-1031. 
Hamond, N.R. \& Fivush, R.(1991) Memories of Mickey Mouse: Young children recount their trip to Disneyworld. Cognitive Development, 6, 433-448.

Harms, T., Clifford, R.M., \& Cryer, D. (2005). Early Childhood Environment Rating Scale Revised Edition. Teachers College Press, New York, NY.

Harms, T., \& Cryer, D. (1999). Video Observations for the ECERS-R. College Teachers Press, New York, NY.

Harms, T., \& Cryer, D. (1999). Video Guide and Training Workbook for the ECERS-R. College Teachers Press, New York, NY.

Harris, P.L., Kavanaugh, R.D., \& Dowson, L. (1997). The depiction of imaginary transformations: early comprehension of a symbolic function. Cognitive Development, 12, 1-19.

Head Start. (2008). U.S. Department of Health and Human Services. Administration for Children and Families. http:/www.acf.hhs.gov/programs/hsb/about/index.html\#mission Last Updated: November 14, 2007; accessed January $27^{\text {th }}$

Helm, J.H., Beneke, S., \& Steinheimer, K. (1998). Windows on learning. Documenting young children's work. New York, NY: Teachers College Press.

Herlitz, A., \& Yonker, J.E. (2002). Sex differences in episodic memory: The influence of intelligence. Journal of Clinical and Experimental Neuropsychology, 24 (1), 107 114.

Hewett, V.W. (2001). Examining the Reggio Emilia approach to early childhood education. Early Childhood Education Journal, 29, 95-100.

Hudson, J.A., Sheffield, E.G., \& Deocampo, J.A. (2006). Effects of representational reminders on young children's recall. In L. Balter \& C. Tamis-LeMonda (Eds.), Child psychology: A handbook of contemporary issues $2^{\text {nd }}$ edition (pp.185-214). New York, NY: Psychology Press.

Jenson, E. (2009). Super Teaching: over 100 Practical Strategies. Corwin Press, Thousand Oaks, California.

Johnson, M.K., Taylor, T.H., \& Raye, C.L. (1977). Fact and fantasy: The effects of internally generated events on the apparent frequency of externally generated events. Memory and Cognition, 5, 116-122.

Jones, H. (1973). The use of visual and verbal memory processes by three-year-old children. Journal of Experimental Child Psychology, 15, 340-351. 
Kail; R. \& Seigel, A.W. (1977). Sex differences in retention of verbal and spatial characteristics of stimuli. Journal of Experimental Child Psychology, 23, 341347.

Katz, L.G. (1995). Lessons from Reggio Emilia: an American perspective. Paper presented at the conference on "Nostaligia del fururo. Liberare speranzo per una nuova cultura dell infanzia" Milano, Italy: October 1995.

Katz, L.G., \& Chard, S.C. (1997). Documentation: the Reggio Emilia approach. Principal, 16-18.

Katz, L.G. (1998). What can we learn from Reggio Emilia? In C. Edwards, L. Gandini \& G.Forman (Eds.), The hundred languages of children: the Reggio Emilia approach-advanced reflections $2^{\text {nd }}$ edition (pp.27-45). Greenwich, CT: Alex Publishing

Lamii; C. (1985). Leading primary education toward excellence: Beyond worksheets and drill. Young Children, 40(6), 3-9.

Landis, J.R., \& Koch, G. G. (1977). The measurement of observer agreement for categorical data. Biometrics, 33, 159-174.

Leichtman, M.D., Pillemer, D.B., Wang, Q., Koreishi, A. \& Han, J.J. (2000). When baby Maisy came to school: Mothers' interview styles and preschoolers' event memories. Cognitive Development, 15, 1-16.

Leichtman, M. D., Wang, Q., \& Pillemer, D.B. (2003). Cultural variations in interdependence and autobiographical memory: Lessons from Korea, China, India, and thé United States. In: R. Fivush \& C.A. Haden (Eds.), Autobiographical memory and the construction of a narrative self: Developmental and cultural perspectives (pp. 73-97) Mahwah, NJ: Lawrence Erlbaum Associates Publishers.

Levin, J. R. (1981). On functions of pictures in prose. In Pirozzolo, F.J., and Wittrock. M.C. (eds.), Neuropsychological and Cognitive Processes in Reading. Academic Pres, New York, pp. 203-228.

Levin, J.R., \& Mayer, R. E. (1993). Understanding illustrations in text. In Britton, B.K., Woodward, A., \& Brinkley, M. (eds). Leaning from Textbooks. Earlbaum. Hillsdale, NJ, pp.95-113.

Lillard, A.S. (2005). Montessori: The Science Behind the Genius. Oxford University Press, USA. 
Lin, L., Hendriks, T., \& Craik, F.I.M. (2007). Age differences in recollection: three patterns of enhanced encoding. Psychology and Aging, 22(2), 269-280.

Live and Learn; About Us. (2008) Retrieved February 3, 2009 from Live and Learn Web Site: http://www.live-learn.org/index.html

Malaguzzi, L. (1998). History, ideas and basic philosophy: An interview with Lella Gandini. In C. Edwards, L. Gandini \& G.Forman (Eds.), The hundred languages of children: the Reggio Emilia approach-advanced reflections $2^{\text {nd }}$ edition (pp.49-97). Greenwich, CT: Alex Publishing.

McFarland, C.E., Duncan, E., \& Bruno, J.M. (1983). Developmental aspects of the generation effect. Journal of Experimental Child Psychology, 36, 413-428.

McGuigan, F., \& Salmon, K. (2004). The time to talk: The influence of timing of adultchild talk on children's event memory. Child Development, 75, 669-686.

Meltzoff, A.N., \& Moore, M.K. (1997). Explaining facial imitation: a theoretical model. Early Development and Parenting, 6 (3-4). 179-192

My School; Dover Country Day School. (2008). Retrieved February 3, 2009 from Pre MZ Web Site: http://www.dover.lib.nh.us/Pre\%20M-Z.pdf.

Nelson, K., \& Fivush, R. (2000). Socialization of memory. In E. Tulving \& F.I.M. Craik (Eds.), The Oxford handbook of memory (pp. 283-295). New York: Oxford University Press.

Ornstien, P.A., Baker-Ward, L., Gordon, B.N., \& Merritt, K.A. (1997). Children's memory for medical experiences. Applied Cognitive Psychology, 11, 87-104.

Ornstien, P.A., \& Haden, C.A. (2001). Memory development of the development of memory? Current Directions in Psychological Science, 10(6) 202-205.

Parault, S.J., \& Schwanenflugel, P.J. (2000). The development of conceptual categories of attention during the elementary school years. Journal of Experimental Child. Psychology, 75, 245-262.

Perlman, M., Zellman, G.L.; \& Le, V. (2004). Examining the psychometric properties of the Early Childhood Rating Scale-Revised (ECERS-R). Early Childhood Research Quarterly, 19, 398-412.

Petrash, J. (2002): Understanding Waldorf Education: Teaching from the Inside Out. Gryphon House, Beltsville, MD. 
Pillemer, D.B. (1998). Momentous vents, vivid memories. Cambridge, MA: Harvard.

Project Zero. (2001). Making learning visible. Children as individual and group learners. Reggio Emilia, Italy: Reggio Children.

Project Zero. (2003). Making Teaching Visible. Documenting individual and group learning as professional development. A making learning visible monograph. Boston, MA: Harvard University.

Reese, E., Haden, C.A., and Fivush, R. (1993). Mother-child conversations about the past: Relationships of style and memory over time. Cognitive development, 8 , 403-430.

Rinaldi, C. (1998). Project curriculum constructed through documentationProgettazione. In C. Edwards, L. Gandini \& G.Forman (Eds.), The hundred languages of children: the Reggio Emilia approach-advanced reflections $2^{\text {nd }}$ edition (pp. 113-125). Greenwich, CT: Alex Publishing

Rinaldi, C. (2006). In dialogue with Reggio Emilia: Listening, researching, and learning. New York, NY: Routledge.

Rusted, J., \& Hodgson, S. (1985). Evaluating the picture facilitation effect in children's recall of written texts. British Journal of Educational Psychology, 55 (3) 288-94.

Schneider, W., \& Bjorklund, D.F. (1998). Memory. In W. Damon (Ed.), Handbook of child psychology (Vol. 2). New York Wiley.

Sheffield, E.G., \& Hudson, J.A. (2006). You must remember this: Effects of video and photograph reminders on 18-month-olds' event memory. Journal of Cognition and Development, 7(1), 73-93.

Slamecka, N.J., \& Graf, P. (1978). The generation effect: Delineation of a Phenomenon. Journal of Experimental Psychology, 4, 592-604.

Sprenger, M. (1999). Learning and Memory: The Brain in Action. ASCD Publishing Alexandria, VA.

Tessler, M, and Nelson, K. (1994). Making memories: The influence of joint encoding on later recall by young children. Consciousness and Cognition, 3, 307-326

Thorton, L., \& Brunton, P. (2005). Understanding the Reggio approach. Great Britain: David Fulton Publishers.

Troseth, G.L., \& DeLoache, J. (1998). The medium can obscure the message: Young children's understanding of video. Child Development, 69, 950-965. 
Vygotsky, L.S. (1978). Mind in society. Cambridge, MA: Harvard University Press.

Wheeler, M.A. (2000). Episodic Memory and Automatic Awareness. In: Tulving, E., \& Craik, I.M. (eds.), The Oxford Handbook of Memory. University Press, Oxford.

Wurm, J.P. (2005). Working in the Reggio way. A beginners guide for American teachers. St Paul, Minnesota: NEACY. 
APPENDICES

.




\section{APPENDIX A}

\section{SCRIPT OF SESSION ONE}

Researcher: "Today we are going to learn about a country. While we are learning my friend here is going to take some pictures of us. We are going to get to talk and touch things as we learn. Do you want to learn with me today? Ok great; who can tell me what a country is? Today we are going to learn about the country of Panama. Who has heard of Panama? Can youtell me anything that you know about Panama?"

Researcher: "Wow you all know so much about what a country is! This map shows Panama, it is a country in Central America. It has two oceans on each side, the Caribbean and Pacific, and it has islands all around it. What else do you see on the map?"

\section{Main Fact: What the Panama flag looks like}

\section{Prop from box: 2 Panama Flags}

Researcher: "What did you pull out from the box? You're right it is a flag, the flag of Panama! What are some things you notice about the flag of Panama? What are the colors on the flag? What are the shapes on the flag?

\section{Sub-fact A: What the star's colors symbolize}

Researcher: "What shape is this on the flag (point to stars)? Are there other flags that have stars? Aren't the colors on the flag wonderful! What colors are the stars? Did you know shapes and colors can mean different things? The blue star on the flag means honesty (telling the truth) and the red star on the flag means laws (following the rules) (Panama - Flag, 2005)"'. 


\section{Sub-fact B: The age of the flag}

Researcher: "You know the flag of Panama is very old too! How old are you? The Flag is much older than that. The Panama flag was made by the first president ever in Panama in 1904. That makes it 104 years old! (Panama - Flag, 2005)."

\section{Sub-fact $C$ : The flag is used in the Carnival celebration}

Researcher: "What do people use flags for? Where do you see flags? People in Panama use their flag in special parades on a holiday called Carnival. Carnival is a 2 day celebration with parades, singing, dancing and lots of great food (Carnival, 2005)."

\section{Main Fact: A bird called a Harpy Eagle lives in Panama Prop from Box: 2 Stuffed Animal Harpy Eagles}

Researcher: "What did you pull out of the box? You're right it is a bird. Do you know what kind of bird this is? This is a special eagle that lives in Panama, it is the national bird and is called a Harpy eagle. Have you ever seen an eagle in New Hampshire? Did it look like this eagle, probably not huh?"

\section{Sub-fact A: Largest eagle in the world}

Researcher: "Are eagles big or small birds? Can you show me with your arms how big eagles are? Harpy eagles are actually the biggest of all eagles all over the world (Harpy, 2005)!"’

\section{Sub-fact B: They eat monkeys}

Researcher: "Do you know what big birds like eagles eat? Do you eat the same things as eagles? Harpy eagles eat a lot of food because they are so big. They mostly eat tree dwelling mammals like monkeys and sloth's (Harpy, 2005)!"

Sub-fact $\mathbf{C}$ : They have nests in rainforest trees 
Researcher: "Where do eagles sleep? Your right in a nest! How do eagles make a nest? Harpy Eagles make their special nests all out of sticks up high in trees in the rainforest (Harpy, 2005)."

\section{Main Fact: In Panama people play a Mejoranera Guitar:}

\section{Prop from box: 2 small native Mejoranera guitars}

Researcher: "What did you pull out of the box? You're right is an instrument, or a guitar!.It's a type of guitar called a Mejoranera. People in Panama like to play folk music with it. Can you try and play a note on that Mejoranera? How does it sound, do you like it?"

\section{Sub-fact A: People also play the violin}

Researcher: "Sometimes people play instruments alone but sometimes they play in a band with other instruments. What other instruments are sometimes in a band? Do you know how to play and instruments? In Panama when people play the Mejoranera people also play the violin. Together the mejoranera and the violin make beautiful. music (Mejoranera, 2003)."

\section{Sub-fact B: Made from one piece of wood}

Researcher: "How do you think people in Panama make a Mejoranera? Have you ever made and instrument? In Panama they carve the mejoranera from a single piece of wood. So there is no glue, tape or nails holding it together, it came from one piece (Mejorana, 2003)."

\section{Sub-fact C: People make up words to songs}

Researcher: "What else do people do when they play music and dance? Sometimes the people who play Mejoraneras also sing. They don't sing songs they know though they make up the words as they go along and have competitions with other singers to see who's song is better (Latin, 2003). Have you ever made up words to a song? Was that a fun thing to do?" 
Researcher: "Wow, we learned a lot today about Panama. You know so much about flags, eagles, and music! That was really a wonderful time and I learned a lot from you. Thank you all for spending this time with me. I will bring you back to your class now!" 


\section{APPENDIX B}

\section{SCRIPT OF SESSION TWO}

\section{Documentation Condition:}

Researcher: "Hello everyone, we met the other day we learned all about à very interesting country called Panama. I want to talk about Panama again by sharing this poster I made with you. Would you like to look at this poster with me? Okay, let's take some time and look at all the things that I put on this poster."

\section{Worksheet Condition:}

Researcher: "Hello, we met the other day we learned all about a very interesting country called Panama. I want to talk about panama again by sharing this spending some time working on a sheet that has some fun games and pictures on it. You will get to do things like color and draw! Do you want to work on this fun sheet with me? Here, take one and we can do them together."

\section{No Reminder Control Group:}

Researcher: "Hello, we met the other day. Today I want to talk about fire safety. Do you know a lot about fire safety? I want to spend some time working on a sheet that has some fun games and pictures on it. You will get to do things like color and draw! Do you want to work on this fun sheet with me? Here, take one and we can do them. together." 
Presentation of New Information:

\section{New Main Fact 1, Picture of the Panama Canal and a boat:}

Researcher: "Do you know what this is? How about this? You are right it is a picture of a river and this is a boat. This river was built by people and is called a canal. This canal is in Panama and connects the two big oceans on each side of the country. The canal lets boats (like this one) get from the ocean on one side of the country over to the ocean on the other side. This canal is called the Panama Canal."

\section{New Main Fact 2, Businessman figure:}

Researcher: "What is this we have here? Yes it is a little man and a picture of a man. What is he wearing, a suit? What might his job. be? Well, really his job is to be the president of Panama! In Panama they have a president just like we do. Who is our president? (George Bush). This man, the president of Panama is a man named Martin. Martin is the presented of Panama and he works to help run the country."

Researcher: "Wow, we did a lot today and we learned a little bit more about Panama. That was really a wonderful time and I learned a lot from you. Thank you all for, spending this time with me. I will bring you back to your class now!" 


\section{APPENDIX C \\ MEMORY INTERVIEW AND SCORECARD}

\section{Memory Interview \& Score Card Participant ID\# \\ Date of interview}

Respond with "great", \& "good job" or "ok" regardless of if the answers were correct. Nod and pause to make sure they are done with their answers before moving on.

\section{Introduction:}

Hello, my name is Caitlin. What is your name? I like that name very much. Well (name) I'm going to ask you some questions and you do the best you can to answer them, okay? Great!

\section{Event Questions (about sessions one \& two):}

I heard that you met with my friend Bethany two times and that you learned about the country of Panama.

I wasn't there those times, but I'm interested in all the things you did when you met with Bethany and learned about Panama.

1) What can you tell me about that?

2) I heard that Bethany gave children some things to hold.

Can you tell me some things that children held? 
Check off item if child mentioned it:

Flag Eagle Guitar Boat Man/Person Map

3) What did you hold?

Check off item if child mentioned it:

Flag Eagle Guitar Boat Man/Person Map

4) I heard that children had a lot to talk about with Bethany those two times you learned about Panama. What are some of the things children said?

5). What did you say?

6) Can you tell me anything else that happened those times when you learned about Panama?

Good job!

\section{Factual Questions:}

\section{Open-Ended Question:}

1) Now I'm interested in finding out everything that you know about the country of Panama. What are some of the things that you can tell me about the country of Panama? (open-ended)

a. Can you tell me anything else?

\section{Item Recognition Question:}


2) I am going to name some things that you might have learned about those times you met with Bethany. You can say "yes" if you learned about the thing and "no" if you didn't. For example, did you learn about a swimming pool with Bethany? No, you didn't. So if I say swimming pool, you would say no.

\begin{tabular}{|l|l|l|l|}
\multicolumn{2}{|c}{ YES } & \multicolumn{2}{c|}{ NO } \\
\hline $\begin{array}{l}\text { Those times you met with } \\
\text { Bethany Did you learn } \\
\text { about a... }\end{array}$ & & & \\
Dog? yes or no? & & & \\
\hline Did you learn about a Bird & & & \\
\hline Did you learn about a Food & & & \\
\hline Did you learn about a Flag & & & \\
\hline Did you learn about a Flute & & & \\
\hline $\begin{array}{l}\text { Did you learn about a } \\
\text { Guitar }\end{array}$ & & & \\
\hline $\begin{array}{l}\text { Did you learn about a } \\
\text { President }\end{array}$ & & & \\
\hline $\begin{array}{l}\text { Did you learn about a } \\
\text { Doctor }\end{array}$ & & & \\
\hline
\end{tabular}

\section{Open-ended and Prompted Questions about Specific Facts:}

Now I'm interested in finding out everything that you know about some things in Panama. So think really hard!

3) Please tell me everything you know about the Panama flag. (open-ended)

a) The stars on the Panama flag mean something. What do they mean? (open-ended) Happiness and sadness honesty and laws other answer 
Now I'll give you two choices:

Do the stars of the flag mean "happiness and sadness" or "honesty and laws"?

b) How old is that Panama flag? (open-ended)

104 650 other answer

Now I'll give you two choices:

Is the Panama flag 104 years old, or 650 years old?

c) People in panama use their flag in a special way. How do people use their flag? (open-ended)

School picnic Holiday parade other answer

Now I'll give you two choices:

Do they use their flag at a school picnic or at a holiday parade?

d) Can you tell me anything else about the Panama flag? (open-ended)

4) Please tell me everything you know about the special bird that lives in Panama. (open ended)

a) The bird is called a Harpy eagle. How big is the Harpy eagle? (open-ended) Small Big other answer

Now I'll give you two choices:

Is the harpy eagle smaller or bigger than you?

b) What does the Harpy eagle eat? (open-ended) Monkeys and Sloth's Flowers and trees other answer

Now I'll give you two choices: 
Does the harpy eagle eat monkeys and sloths or does he eat flowers and trees?

c) Birds don't sleep in beds like we do. Where does the Harpy eagle sleep? (openended)

Cave Nest other answer

Now I'll give you two choices:

Does the harpy eagle sleep in a cave or in a nest?

d) Can you tell me anything else about the Harpy Eàgle? (open-ended)

5) Please tell me everything you know about the guitar that people in Panama play? (open-ended)

a) The guitar is called the major-an-ara guitar.) When people play the major-an-ara guitar they also play another instrument. What is the other instrument they play? (open-ended)

Violin__ Trumpet___ other answer

Now I'll give you two choices:

Do they play a violin or a trumpet?

b) What is the major-an-ara guitar made from? (open-ended) Large piece of plastic one piece of wood other answer

Now I'll give you two choices:

Is the guitar made from a large piece of plastic or one piece of wood?

c) When people play the major-an-ara guitar what else do they do? (open-ended) 
Sing songs Tap dance other answer:

Now I'll give you two choices:

Do they sing songs or do they tap dance ?

d) Can you tell me anything else about the major-an-ara guitar? (open-ended)

6) Please tell me everything you know about the special river in Panama. (open-ended)

a.) What is that special river in Panama called? (open-ended)

Panama Fjord Panama Canal other answer

Now I'll give you two choices:

Is it called the Panama Fjord or the Panama Canal?

b) How was the Panama Canal made? (open-ended) Water and rocks/Nature People by digging it other answers

Now I'll give you two choices:

Did nature make it with water and rocks or did people make it by digging it?

c) Can you tell me anything else about the Panama Canal? (open-ended)

7) Please tell me everything you know about the president of Panama. (open-ended)

a.) What is the name of the president of Panama? (open-ended)

Martin Robert Other answer

I'll give you two choices:

Is his name Martin or Robert? 
b.) What does a president do in his job? (open-ended)

Fly an airplane

Run the country

other answer

Now I'll give you two choices:

Does he fly an airplane or does he run the country?

\section{Recognition Questions:}

Ok, now I am going to show you some pictures. This is fun for children, I think you will like it!

1) Which one of these flags is the Panama Flag? Number they pointed to:
(14. I.
1)
2)

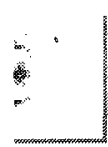
3)
4)

2) Which one of these birds is the Harpy Eagle that lives in Panama?

Number they pointed to:

1)

2) $\therefore \quad \cdots$

3)
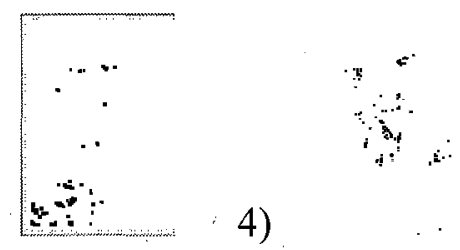

4) 
3) Which one of these guitars is the Major-an-ara Guitar that people in Panama play? Number they pointed to:

1)

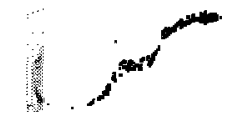

2)

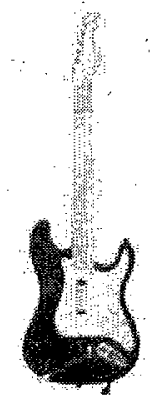

3)

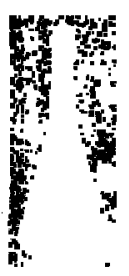

4)

4) Can you show me where on this map the Panama Canal is?

Did they point to it? YES

$\mathrm{NO}$

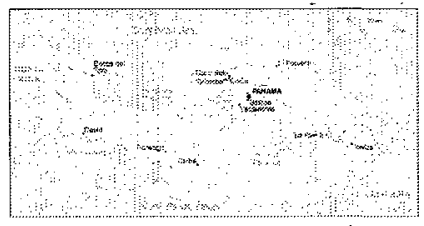

5) Which one of these men is the president of Panama?

Number they pointed to:

1)

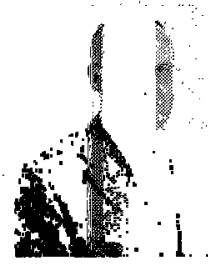

2)

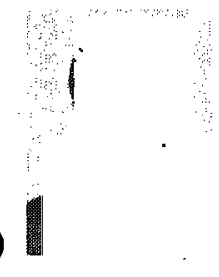

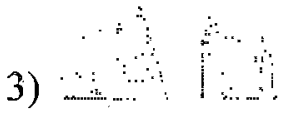

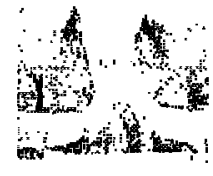

4)

Ok, great! We are almost done, just a few more questions. 


\section{Source Monitoring Questions:}

You met with Bethany two times to learn about Panama. The first time was with a big group of children, and the second time was just with Bethany and maybe one other child. Now I want to you think really hard and tell me which time you learned about the things I'm going to name.

Check off the answer the child chooses.

Which time did you learn about the Harpy Eagle that lives in Panama?

The first time, with a big group of children or the second time?

Which time did you learn about the president of Panama?

The first time, with a big group of children or the second time?

Which time did you learn about the flag of Panama?

The first time, with a big group of children or the second time?

Which time did you learn about the Panama canal?

The first time, with a big group of children or the second time?

Great job! Thank you for answering my questions. Let's go back to your class now. 


\section{APPENDIX D}

MEMORY INTERVIEW SUMMARY SCORCARD

Summary Score Card

Participant Gender: $M=1$.

$$
\mathrm{F}=2
$$

Participant School: Garrison $=1 \quad$ CSDC $=2$

Growing Places $=3 \quad$. My School $=4$

Live and Learn $=5$

\section{Participant ID \#}

\section{Participant Classroom: Preschool $=1 \quad$ Kindergarten $=2$}

Participant DOB

Age in Months:

\section{Event Questions (about sessions one \& two):}

Can you tell me some things that children held? (open)

Check off ones child said:

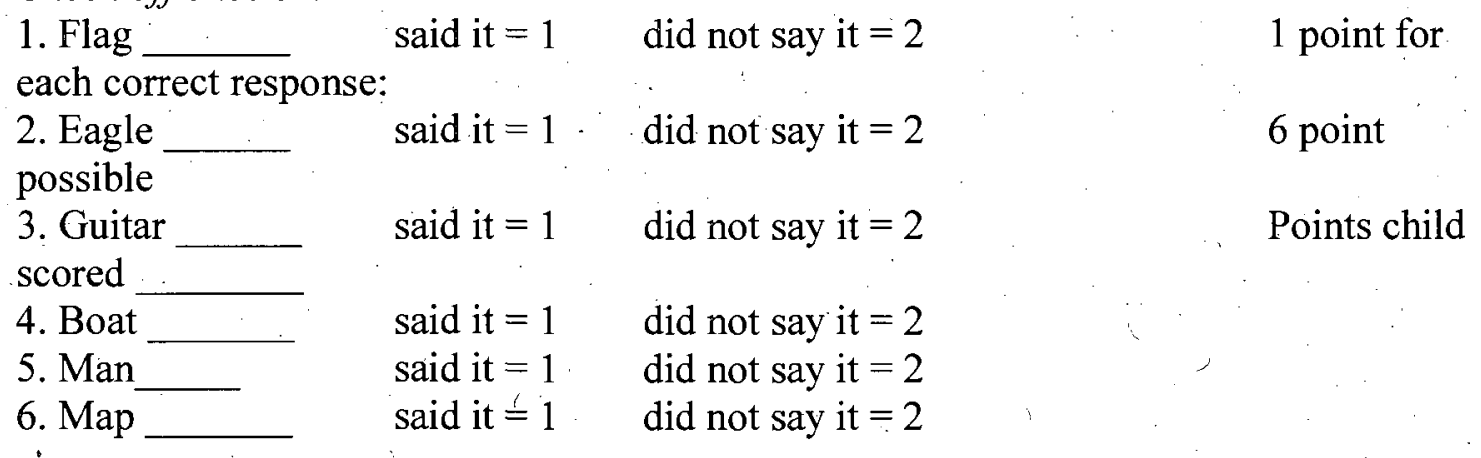


What did you hold?

What did the child really hold session $1 \#$

(All children held boat and man.)

1 Flag

2. Eagle

3 Guitar

4 Boat

5 Man

6 Map said it and held it $=1$

did not say it but held it $=3$

said it and held it $=1$

did not say it but held it $=3$

said it and held it $=1$

did not say it but held it $=3$

said it and held it $=1$

did not say it but held it $=3$

said it and held it $=1$

did not say it but held it $=3$.

said it and held it $=1$

did not say it but held it $=3$ said it but did not hold it $=2$

did not say it and did not hold it $=4$

said it but did not hold it $=2$

did not say it and did not hold it $=4$

said it but did not hold it $=2$

did not say it and did not hold it $=4$

said it but did not hold it $=2$

did not say it and did not hold it $=4$

said it but did not hold it $=2$

did not say it and did not hold it $=4$

said it but did not hold it $=2$

did not say it and did not hold it $=4$

\section{Factual Questions:}

\section{Item Recognition Question:}

Did you learn about a:

Dog Yes: Incorrect $=1 \quad$ No: Correct $=2 . \quad$ no answer $=3$

Bird no: Incorrect $=1$ yes: Correct $=2$ no answer $=3$

Food Yes: Incorrect $=1 \quad$ No: Correct $=2 \quad$ no answer $=3$

$\begin{array}{llcl}\text { Flag: } & \text { No: } \text { Incorrect }=1 & \text { Yes: } \text { Correct }=2 & \text { no answer }=3 \\ \text { flute } & \text { yes: Incorrect }=1 & \text { no: } \text { Correct }=2 & \text { no answer }=3 \\ \text { Guitar } & \text { no: Incorrect }=1 & \text { Yes: } \text { Correct }=2 & \text { no answer }=3 \\ \text { President } & \text { no: Incorrect }=1 & \text { Yes: } \text { Correct }=2 & \text { no answer }=3 \\ \text { Doctor } & \text { Yes: Incorrect }=1 & \text { No: Correct }=2 & \text { no answer }=3\end{array}$




\section{Open-ended and Prompted Questions about Specific Facts:}

The stars on the Panama flag mean something. What do they mean? (open)

Correct answer given (honesty and laws) $=1$

Other Incorrect answer given $=2$

No answer given $=3$

Do the stars of the flag mean:

Correct answer given (honesty and laws) $=1$

Other incorrect answer given: (happiness and sadness) $=2$

No answer given $=3$

How old is that Panama flag? (open)

Correct answer given $(104$ years $)=1$

Other Incorrect answer given $=2$

No answer given $=3$

Is the Panama flag

Correct answer given (104 years) $=1$

Other Incorrect answer given $(650$ years $)=2$

No answer given $=3$

People in panama use their flag in a special way. How do people use their flag? (open)

Correct answer given (in parade) $=1$

Other Incorrect answer given $=2$

No answer given $=3$

Do they use their flag at a

Correct answer given (in parade) $=1$

Other Incorrect answer given (school picnic) $=2$

No answer given $=3$

How big is the Harpy eagle? (open)

Correct answer given (big) $=1$

Other Incorrect answer given $=2$

No ànswer given $=3$

Is the harpy eagle than you?

Correct answer given (bigger) $=1$

Other Incorrect answer given (smaller) $=2$

No answer givén $=3$

What does the Harpy eagle eat? (open)

Correct answer given (monkeys and sloths) $=1$

Other Incorrect answer given $=2$

No answer given $=3$

Does the harpy eagle eat

Correct answer given (monkeys and sloths) $=1$

Other Incorrect answer given (flowers and trees) $=2$

No answer given $=3$

Where does the Harpy eagle sleep? (open)

Correct answer given (nest) $=1$

Other Incorrect answer given $=2$

No answer given $=3$ 
Does the harpy eagle sleep

Correct answer given (nest) $=1$

Other Incorrect answer given (cave) $=2$

No answer given $=3$

When people play the major-an-ara guitar they also play another instrument. What is the other instrument they play? (open)

Correct answer given $($ violin $)=1$

Other Incorrect answer given $=2$

No answer given $=3$

Do they play a

Correct answer given $($ violin $)=1$

Other Incorrect answer given (trumpet) $=2$

No answer given $=3$

What is the major-an-ara guitar made from? (open)

Correct answer given $(1$ piece of wood $)=1$

Other Incorrect answer given $=2$

No answer given $=3$

Is the guitar made from a

Correct answer given $(1$ piece of wood $)=1$

Other Incorrect answer given (large piece of plastic) $=2$

No answer given $=3$

When people play the major-an-ara guitar what else do they do? (open)

Correct answer given (sing songs) $=1$

Other Incorrect answer given $=2$

No answer given $=3$

Do they

Correct answer given (sing songs) $=1$

Other Incorrect answer given (tap dance) $=2$

No answer given $=3$

What is that special river in Panama called? (open)

Correct answer given (panama canal) $=1$

Other Incorrect answer given $=2$

No answer given $=3$

Is it called the

Correct answer given (panama canal) $=1$

Other Incorrect answer given (panama fjord) $=2$

No answer given $=3$

How was the Panama Canal made? (open)

Correct answer given (people by digging it) $=1$

Other Incorrect answer given $=2$

No answer given $=3$

Was it made by

Correct answer given (people by digging it) $=1$

Other Incorrect answer given (nature with water and rocks) $=2$

No answer given $=3$ 
What is the name of the president of Panama? (open)

Correct answer given (Martin) $=1$

Other Incorrect answer given $=2$

No answer given $=3$

Is his name

Correct answer given $($ Martin $)=1$

Other Incorrect answer given (Robert) $=2$

No answer given $=3$

What does a president do in his job? (open)

Correct answer given (run the country) $=1$

Other Incorrect answer given $=2$

No answer given $=3$

Does he

Correct answer given (run the country) $=1$

Other Incorrect answer given (fly a plane) $=2$

No answer given $=3$

What did child hold in session one

Open ended questions correct for that prop

Choice questions correct for that prop

Total correct for that prop

\section{Recognition Questions:}

Panama Flag:

Number they pointed to:

3 is correct, are they correct? $\quad 1=$ correct $\quad 2=$ wrong

Harpy Eagle:

Number they pointed to:

2 is correct, are they correct? $\quad 1=$ correct $\quad 2=$ wrong

Major-an-ara Guitar:

Number they pointed to:

1 is correct, are they correct?

$$
1=\text { correct } \quad 2=\text { wrong }
$$

Panama Canal:

Did they point to it?

$$
1=\mathrm{YES} \quad 2=\mathrm{NO}
$$

President of Panama

Number they pointed to:

2 is correct, are they correct? $\quad 1=$ correct $\quad 2=$ wrong

Total correct recognition questions

Total incorrect recognition questions

\section{Source Monitoring Questions:}

$1=$ correct

$2=$ incorrect

$3=$ no answer given -

Harpy Eagle:

The first time

second time

$$
\begin{aligned}
& =1 \\
& =2
\end{aligned}
$$



no answer
$=3$
President of Panama:
The first time
$=2$
second time
no answer
$=1$
Flag of Panama:
The first time
second time
$=3$
no answer
$=1$
Panama canal:
The first time
second time
$=2$
$=3$
no answer
$=2$
$=1$
$=3$

Total source monitoring questions correct

Total source monitoring questions incorrect 


\section{APPENDIX E}

\section{TRANSCRIPTION CODING TEMPLATE}

\section{Memory Transcription Coding Template \\ Participant ID\# \\ Date of interview}

\section{Event Questions (about sessions one \& two):}

1) What can you tell me about that?

a) Correct Objects

b) Flag

$$
\text { Boat_ Eagle (Harpy) }
$$
Guitar (Mejoranera) Map

c) Other correct statement (from the list) circle items on list

d) Incorrect objects (any object/noun not on the list)

e) Mentions of something someone else did during the event

f) Mentions of something the child did during the event

g) Total Word Count

4) I heard that children had a lot to talk about with Bethany those two times you learned about Panama. What are some of the things children said?

a) Correct Objects

b) Flag Eagle (Harpy) Boat Man Guitar (Mejoranera) Map 
c) Other correct statement (from the list) circle items on list

d) Incorrect objects (any object/noun not on the list)

e) Mentions of something someone else did during the event

f) Mentions of something the child did during the event (not I remember, that is not during the event)

g) Total Word Count

5) What did you say?

a) Correct Objects

b) Flag Boat_ Eagle (Harpy) Guitar (Mejoranera) Map

c) Other correct statement (from the list) circle items on list

d) Incorrect objects (any object/noun not on the list)

e) Mentions of something someone else did during the event

f) Mentions of something the child did during the event not during the event)

g) Total Word Count

6) Can you tell me anything else that happened those times when you learned about Panama?

a) Correct Objects

b) Flag

Boat__ Ea
Eagle (Harpy) Man Guitar (Mejoranera) Map

c) Other correct statement (from the list) circle items on list

d) Incorrect objects (any object/noun not on the list)

e) Mentions of something someone else did during the event 
f) Mentions of something the child did during the event (not I remember, that is not during the event)

g) Total Word Count

\section{Factual Questions:}

3) What are some of the things that you can tell me about the country of Panama? (open-ended)

Can you tell me anything else?

a) Correct Objects

b) Flag Eagle (Harpy) Man Guitar (Mejoranera) Map Boat

c) Other correct statement (from the list) circle items on list

d) Incorrect objects (any object/noun not on the list)

e) Mentions of something someone else did during the event

f) Mentions of something the child did during the event (not I remember, that is not during the event)

g) Total Word Count

\section{Prompted Questions about Specific Facts:}

3) Please tell me everything you know about the Panama flag. (open-ended)

Can you tell me anything else about the Panama flag? (open-ended)

a) Other correct statement (from the list) circle items on list

b) Incorrect objects (any object/noun not on the list)

c) Mentions of something someone else did during the event

d) Mentions of something the child did during the event (not I remember, that is not during the event) 
e) Total Word Count

4) Please tell me everything you know about the special bird that lives in Panama. (open ended)

Can you tell me anything else about the Harpy Eagle? (open-ended)

a) Other correct statement ___ (from the list) circle items on list

b) Incorrect objects ___ (any object/noun not on the list)

c) Mentions of something someone else did during the event

d) Mentions of something the child did during the event ___ (not I remember, that is not during the event)

e) Total Word Count

5) Please tell me everything you know about the guitar that people in Panama play? (open-ended)

Can you tell me anything else about the major-an-ara guitar? (open-ended)

a) Other correct statement ____ (from the list) circle items on list

b) Incorrect objects ___ (any object/noun not on the list)

c) Mentions of something someone else did during the event

d) Mentions of something the child did during the event not during the event)

e) Total Word Count

6) Please tell me everything you know about the special river in Panama. (open-ended)

Can you tell me anything else about the Panama Canal? (open-ended)

a) Other correct statement _____ (from the list) circle items on list

b) Incorrect objects (any object/noun not on the list) 
c) Mentions of something someone else did during the event

d) Mentions of something the child did during the event not during the event)

e) Total Word Count

7) Please tell me everything you know about the president of Panama. (open-ended)

a) Other correct statement (from the list) circle items on list

b) Incorrect objects (any object/noun not on the list)

c) Mentions of something someone else did during the event

d) Mentions of something the child did during the event not during the event)

e) Total Word Count

TOTAL WORD COUNT (from the whole transcript)

Correct objects: must come from the list under the question

Other correct statement: must come from the list below. Be liberal and give children credit if they are mentioning part or conveying the idea.

Incorrect object: any object not on either list. It might sound like it could be true but if it is not on the list as a fact that we learned count it here.

Mentions of something someone else did: must be a verb, something that was done when the learning event occurred. It is a clear reference to the past. Count each one so if they say "I held" three times it countś 3 times.

Mentions of something the child did: same as above

Total words: count each one

Correct Statements List:

* Red Star

* Blue Star

* red star means rules and laws

* blue star means honesty and truth

* Red on flag

* blue on flag

* white on flag 
* same colors as the usa flag

* 104 years old

* older than me

* flag was made by the first president

* used in parade

* used in carnival

* Biggest eagle or mention of big size

* Bigger than me

Eat monkeys

* Eat sloth's

* Eat tree dwelling mammals

- Sleep in a nest

* Nest is in a tree

- Nest is made of sticks

* Play in a band

* Makes music

* Play with violin

* Carved

Made from one piece of wood

* No tape nails, or glue holding it together

* People sing songs

* People make up the words to the songs

* People sing in competitions

* Panama canal

* Built by people

* Connects one ocean to the other

Boats use it

* Presidents name is Martin

* President helps run the country

* President makes laws

* Pictures (of objects)

* River

* Wings 
APPENDIX F

IRB APPROVAL LETTER 


\section{University of New Hampshire}

Research Conduct and Compliance Services, Office of Sponsored Research Service Building, 51 College Road, Durham, NH 03824-3585

Fax: 603-862-3564

29-Jul-2008

Fleck, Bethany

Psychology, Conant Hall

68 Sixth Street

Dover, NH 03820

IRB \#: 4338

Study: The Effects of Documentation on Young Children's Memory

Approval Date: 28-Jul-2008

The Institutional Review Board for the Protection of Human Subjects in Research (IRB) has reviewed and approved the protocol for your study as Expedited as described in Title 45 , . Code of Federal Regulations (CFR), Part 46, Subsection 110.

Approval is granted to conduct your study as described in your protocol for one year from the approval date above. At the end of the approval period, you will be asked to submit a report with regard to the involvement of human subjects in this study. If your study is still active, you may request an extension of IRB approval.

Researchers who conduct studies involving human subjects have responsibilities as outlined in the attached document, Responsibilities of Directors of Research Studies Involving Human Subjects. (This document is also available at http://www: unh.edu/osr/compliance/irb.html.) Please read this document carefully before commencing your work involving human subjects.

If you have questions or concerns about your study or this approval, please feel free to contact me at 603-862-2003 or Julie.simpson@unh.edu. Please refer to the IRB \# above in all correspondence related to this study. The IRB wishes you success with your research.

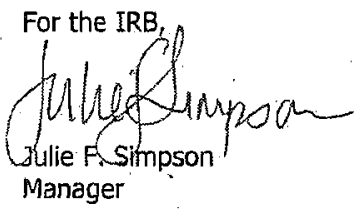

cc: File

Leichtman, Michelle 